\title{
In Silico Characterization of Calcineurin from Pathogenic Obligate Intracellular Trypanosomatids: Potential New Biological Roles
}

\author{
Patricio R. Orrego ${ }^{1, *}$, Mayela Serrano-Rodríguez ${ }^{2}$, Mauro Cortez ${ }^{3}$ and Jorge E. Araya ${ }^{2,4, *}$ \\ 1 Departamento Biomédico, Facultad de Ciencias de la Salud, Universidad de Antofagasta, \\ Antofagasta 1270300, Chile \\ 2 Departamento de Tecnología Médica, Facultad de Ciencias de la Salud, Universidad de Antofagasta, \\ Antofagasta 1270300, Chile; mayela.serrano@uantof.cl \\ 3 Departamento de Parasitologia, Instituto de Ciências Biomédicas, Universidade de São Paulo, \\ São Paulo 05508-000, Brazil; mcortez@usp.br \\ 4 Center for Biotechnology and Bioengineering, CeBIB, Universidad de Antofagasta, \\ Antofagasta 1270300, Chile \\ * Correspondence: patricio.orrego@uantof.cl (P.R.O.); jorge.araya@uantof.cl (J.E.A.); \\ Tel.: +56-55-2637664 (J.E.A.)
}

check for updates

Citation: Orrego, P.R.; Serrano-Rodríguez, M.; Cortez, M.; Araya, J.E. In Silico Characterization of Calcineurin from Pathogenic Obligate Intracellular Trypanosomatids: Potential New Biological Roles. Biomolecules 2021, 11, 1322. https://doi.org/10.3390/ biom11091322

Academic Editor: Mark S. Johnson

Received: 15 May 2021

Accepted: 9 August 2021

Published: 7 September 2021

Publisher's Note: MDPI stays neutral with regard to jurisdictional claims in published maps and institutional affiliations.

Copyright: (c) 2021 by the authors. Licensee MDPI, Basel, Switzerland. This article is an open access article distributed under the terms and conditions of the Creative Commons Attribution (CC BY) license (https:// creativecommons.org/licenses/by/ $4.0 /)$.

\begin{abstract}
Calcineurin ( $\mathrm{CaN})$ is present in all eukaryotic cells, including intracellular trypanosomatid parasites such as Trypanosoma cruzi (Tc) and Leishmania spp. (Lspp). In this study, we performed an in silico analysis of the CaN subunits, comparing them with the human $(\mathrm{Hs})$ and looking their structure, post-translational mechanisms, subcellular distribution, interactors, and secretion potential. The differences in the structure of the domains suggest the existence of regulatory mechanisms and differential activity between these protozoa. Regulatory subunits are partially conserved, showing differences in their $\mathrm{Ca}^{2+}$-binding domains and myristoylation potential compared with human CaN. The subcellular distribution reveals that the catalytic subunits TcCaNA1, TcCaNA2, LsppCaNA1, LsppCaNA1_var, and LsppCaNA2 associate preferentially with the plasma membrane compared with the cytoplasmic location of $H s \mathrm{CaNA} \alpha$. For regulatory subunits, $H s \mathrm{CaNB}-1$ and LsppCaNB associate preferentially with the nucleus and cytoplasm, and TcCaNB with chloroplast and cytoplasm. Calpain cleavage sites on CaNA suggest differential processing. CaNA and CaNB of these trypanosomatids have the potential to be secreted and could play a role in remote communication. Therefore, this background can be used to develop new drugs for protozoan pathogens that cause neglected disease.
\end{abstract}

Keywords: calcineurin; in silico analysis; intracellular trypanosomatids; Leishmania; Trypanosoma cruzi

\section{Introduction}

People all over the world are affected by leishmaniasis and American trypanosomiasis, two neglected tropical diseases that infect over 6 and 12 million people, respectively [1-3]. Several issues, including a lack of safe/optional drugs, parasite resistance, and ineffective insect vector control, have caused researchers to race to develop more effective treatments for diseases [4], increasing the current alternative studies with promising results [5-7]. These vector-borne diseases are caused by protozoan parasites of the Trypanosomatidae family, Leishmania spp. (Lspp) and Trypanosoma cruzi (Tc), which have unique characteristics. Insect vectors release infective parasite forms during the blood meal in humans, where they face harsh extracellular conditions and quickly invade cells to avoid extracellular immune response [8,9]. It is well established that these intracellular parasites infect different cells, activating the release of $\mathrm{Ca}^{2+}$ from intracellular stores $[10,11]$ from both parasite and host cells, stimulating different signaling pathways that promote critical interactions. $\mathrm{Ca}^{2+}$-dependent phosphatases have thus emerged as critical regulator molecules [12] for intracellular trypanosomatids. 
Calcineurin (CaN, also called protein 2B phosphatase, $\mathrm{PP} 2 \mathrm{~B})$ is the main binding enzyme to the multifunctional protein calmodulin $(\mathrm{CaM})$ in the brain and the only serine/threonine phosphatase under the control of $\mathrm{Ca}^{2+} / \mathrm{CaM}$, playing a critical role in $\mathrm{Ca}^{2+}$-mediated cellular responses [13-16]. Stimulation of $\mathrm{CaN}$ by CaM ensures the coordinated regulation of its phosphatase function with the activities of many other enzymes, including $\mathrm{Ca}^{2+}$ and $\mathrm{CaM}$ control-dependent kinases. $\mathrm{CaN}$ is widely distributed, despite its abundance in nervous tissues, and its structure is highly conserved from yeast to human [15]. CaN is a heterodimer composed of two subunits: a catalytic subunit A (CaNA) and a regulatory subunit $B(\mathrm{CaNB})$ [17].

CaN biology is distinguished by the specificity of its substrates, which include transcription factors, specific inhibitors, ion channels, apoptotic molecules, and cytoskeletal proteins [18]. In mammals, the CaNA active site has a mass ranging from 57 to $59 \mathrm{kDa}$ depending on the isoform [17]. Its amino acid structure is highly conserved in eukaryotes, as all CaNA genes encode a polypeptide consisting of a catalytic domain, homologous to other protein phosphatases, and three regulatory domains at the C-terminus that distinguish $\mathrm{CaN}$ from other members of the PPP family such as PP1 and PP2C [17]. These three domains have been identified as the CaNB-binding domain $[19,20]$, the CaM-binding domain [21,22], and the autoinhibitory domain (AID) [20,23], which binds to the CaN active site in the absence of $\mathrm{Ca}^{2+} / \mathrm{CaM}$, inhibiting the enzyme and acting in concert with the CaM-binding domain, regulating this last domain [24].

$\mathrm{CaN}$ has gained importance since its discovery as the target of the immunosuppressive drugs cyclosporin A (CsA) and tacrolimus (FK506) [25], which inhibit CaN when complexed with their respective cytoplasmic receptors (CyP) or FK506-binding proteins (FKBP), respectively, both complexes that block access to the active site of substrates [25-27].

The $\mathrm{Ca}^{2+}-\mathrm{CaN}$ signaling pathway is conserved in many eukaryotic microorganisms $[28,29]$, making it an appealing target for the development of new anti-pathogen drugs [12]. In fact, studies in yeasts such as Saccharomyces cerevisiae show that CaN plays an important role in the microorganism's survival by dephosphorylating the transcription factor Crz1, which moves it from the cytosol to the nucleus, subsequent to the activation of $\mathrm{CaN}$ [30]. In the case of protists, the lack of transcription factors [31] suggests that this $\mathrm{CaN}$ pathway operates by a different mechanism [12] in cellular processes such as adherence to the host cell, cell invasion, thermo-tolerance, and flagellar motility [12]. Notably, in human protozoan pathogens such as T. cruzi, the role of $\mathrm{CaN}$ has been linked to processes of cellular invasion of infective forms and proliferation of non-infective forms of the parasite [32,33]. CaN of Leishmania spp., on the other hand, has been linked to an important role in thermo-tolerance and survival processes in mammalian hosts [34], being associated with flagellar motility, response to environmental changes, survival, and virulence [35].

In this paper, we perform an in silico characterization of the catalytic and regulatory CaN subunits of the obligate intracellular trypanosomatids, T. cruzi, and Leishmania spp., comparing them to human $\mathrm{CaN}$ subunits.

\section{Materials and Methods}

\subsection{Database Inspection}

The sequences corresponding to the catalytic $\mathrm{A} 1, \mathrm{~A} 2$, and $\mathrm{CaN}$ regulatory subunits in T. cruzi and Leishmania spp. were obtained from the NCBI protein databases (https:/ /www.ncbi.nlm.nih.gov/ (accessed on 4 April 2020)) and TriTrypDB (https:/ / tritrypdb.org/tritrypdb / (accessed on 4 April 2020)) [36] and used as references; those characterized in T. cruzi included CAI48024 and CAI48025 [37], ABY61052 and ABO14295 [32], and ADN03392 [33] and those characterized in Leishmania included LmjF.26.2530 [38], LmjF.36.1980 [38,39], and LmjF.21.1630 [36].

In the case of the $\mathrm{A} 1$ catalytic and $\mathrm{CaN}$ regulatory subunits in Homo sapiens, the sequences NP_000935 and NP_000936 (National Center for Biotechnology Information (NCBI) were used. Bethesda (MD): National Library of Medicine (US), National Center for 
Biotechnology Information; (1988)—[cited 6 January 2021]. Available from https:/ / www. ncbi.nlm.nih.gov / (accessed on 01 January 2021)).

\subsection{Obtaining Consensus Sequences and Multiple Alignment of $\mathrm{CaN}$}

The consensus amino acid sequences of the catalytic A1, A2, and CaN regulatory subunits of T. cruzi and Leishmania spp. were obtained using the EMBOSS Cons tool (https: / /www.ebi.ac.uk/Tools/msa/emboss_cons/ (accessed on 30 May 2020)) (Supplementary File 1) [40]. The multiple alignment of trypanosomatids and $H$. sapiens was performed in the MEGA7 software [41] using the default ClustalW parameters. The alignments obtained were viewed in the SnapGene Viewer software (version 5.1.3, from GSL Biotech; available at snapgene.com).

\subsection{Evaluation of Conserved Domains, Determination of Physicochemical Parameters, and Hydrophobicity Profiles}

The identification of the conserved domains of the sequences under study was carried out through the Conserved Domains Database (CDD) [42-44] and ExPASy ScanProsite (https:/ / prosite.expasy.org/scanprosite/ (accessed on 30 May 2020)) [45]. The domain structure was represented by PROSITE 'MyDomains' image creator tool [46].

The determination of the physicochemical parameters was carried out in the ProtParam tool (https:/ / web.expasy.org/protparam/protparam-doc.html (accessed on 30 May 2020)) [47] and the hydrophobicity profiles with the Kyte-Doolittle algorithm [48], with a window of nine residues in ProtScale (https:/ / web.expasy.org/protscale/ (accessed on 30 May 2020)) [47].

\subsection{In Silico Identification of Protein-Protein Interactions of CaN Regulatory Subunits}

The identification of interactions of the CaNB subunits of T. cruzi (accession number ABO14295) and L. major (accession number LmjF.21.1630) was carried out in the search tool for the recovery of interacting genes/proteins, STRING V.11.0 (https://string-db. org / (accessed on 11 June 2020)) [49]. The resources used were experimental results and databases, with a value of 0.7 (high confidence) established as the minimum interaction score [49].

Similarly, the sequences of the CaN regulatory subunits of T. cruzi (accession number TcCLB.510519.60) and L. major (accession number LmjF.21.1630) were entered as proteins consulted in the TrypsNetDB databases (trypsNetDB.org) [50].

\subsection{Prediction of the Subcellular Localization of CaN in Pathogenic Intracellular Trypanosomatids}

The subcellular location of the CaN subunits in T. cruzi and Leishmania spp. was carried out in WoLF PSORT (https: / / wolfpsort.hgc.jp / (accessed on 11 June 2020)) [51] with Fungi selected as the type of organism; in addition, the CELLO2GO tool was also used (http: / / cello.life.nctu.edu.tw / cello2go (accessed on 11 June 2020)) by selecting Eukaryotes [52].

\subsection{Prediction of Entry to the Non-Classical Secretory Pathway of CaN in Pathogenic Intracellular Trypanosomatids}

The SecretomeP 2.0 Server tool (http:/ / www.cbs.dtu.dk/services/SecretomeP/ (accessed on 11 June 2020)) was used to predict the entry of the different CaN subunits into the non-classical secretory pathway using the prediction for mammalian sequences [53] with a threshold of 0.6 .

\subsection{Prediction of Cleavage by Calpains in CaN Catalytic Subunits of Pathogenic Intracellular Trypanosomatids}

The prediction of potential calpain cleavage sites was determined using GPS-CDD (version 1.0 available at http:/ / ccd.biocuckoo.org/ (accessed on 7 July 2020)) with a high threshold with a cut-off of 0.654 [54]. As a reference sequence, the catalytic subunit alpha isoform from $H$. sapiens (accession number NP_000935) was used. 
2.8. Prediction of Phosphorylation Sites in the CaM-Binding Domain (CaM-BD) of CaN Catalytic Subunits from Leishmania Spp.

Predicted phosphorylation sites were evaluated using NetPhos 3.1, a web server (http://www.cbs.dtu.dk/services/NetPhos/ (accessed on 27 July 2020)) $[55,56]$. Sites with a threshold $>0.5$ were included in the results.

\section{Results}

3.1. The CaN Subunits of Obligate Intracellular Trypanosomatids Possess Diverse, Partially Conserved Domain Architecture and Potential Calpain Cleavage Sites

The molecular masses estimated by ProtParam (https:/ / web.expasy.org/protparam/ (accessed on 30 May 2020)) for the catalytic CaN subunits of T. cruzi are $44 \mathrm{kDa}$ for TcCaNA1 and $45 \mathrm{kDa}$ for TcCaNA2, while for Leishmania spp., the consensus sequences are $60 \mathrm{kDa}$ for LsppCaNA1, $56 \mathrm{kDa}$ for LsppCaNA1_var, and $45 \mathrm{kDa}$ for LsppCaNA2 (Table 1). This reflects a diverse structural degree, evidenced in the domain structure of the deduced amino acid sequences under study (Figure 1), when compared with the catalytic sequence of human $\mathrm{CaN}$ with its three domains (binding to $\mathrm{CaNBm}$, binding to CaM, and to AID). The TcCaNA1 and TcCaNA2 subunits possess the CaNB-binding (CaNB-BD) and catalytic domain, in the same way as LsppCaNA2 from Leishmania spp. However, LsppCaNA1 and LsppCaNA1_var possess all the domains present in human CaN. Interestingly, CaNA2 are those that have a higher $\mathrm{pI}$ (isoelectric point) than their A1 counterparts (4.83-5.61), with pI of 8.13 for TcCaNA2 and 6.37 for LsppCaNA2.

Table 1. Overview of the physical and chemical parameters of CaN.

\begin{tabular}{cccc}
\hline Protein & \#aa & MW (Da) & pI \\
\hline HsCaNA $\alpha$ & 521 & $58,687.85$ & 5.58 \\
TcCaNA1 & 382 & $43,244.64$ & 4.83 \\
TcCaNA2 & 392 & $44,619.50$ & 8.13 \\
LsppCaNA1 & 545 & $59,747.65$ & 5.00 \\
LsppCaNA1_var & 503 & $55,559.36$ & 5.61 \\
LsppCaNA2 & 407 & $45,138.00$ & 6.37 \\
TcCaNB & 176 & $19,458.18$ & 4.98 \\
LsppCaNB & 176 & $19,785.54$ & 4.60 \\
\hline
\end{tabular}

The potential calpain cleaved sites determined in GPS-CDD (from more sites to fewer sites) are as follows; 29 for LsppCaNA1, 12 for TcCaNA2, 9 for LsppCaNA1_var, 5 for LsppCaNA2, and 3 for TcCaNA1. $H s C a N A \alpha$ has 19 sites (Figure 1).

In relation specifically to the CaNB-BD domain, the hydrophobicity profile in Leishmania spp. is more similar to the human subunit $\left(H_{s} \mathrm{CaNA} \alpha\right)$ than in the catalytic subunits of $T$. cruzi, presenting the highest hydrophobic profile in LsppCaNA2 (Figure 2F), when compared with the other catalytic subunits of CaN (Figure 2). When CaNB-BD is analyzed among all sequences, we observe that there are two mainly hydrophobic regions that go from amino acid M347 to amino acid S373 (Figure 3, highlighted in squares). These hydrophobic regions are partially conserved, the first one (region 1, on the left) with a higher degree of conservation in relation to $H_{s} \mathrm{CaNA} \alpha$. Particularly, in the sequence MDVFTWSLPFV (region 1) of CaNB-BD, the amino acid V ${ }^{349}$ changes in every catalytic subunit of intracellular trypanosomatids, with only one residue $\left(\mathrm{L}^{369}\right)$ being conserved in the second hydrophobic region (region 2, EMLVNVLNICS) of $H s C a N A \alpha$, except in TcCaNA1 (Figure 3). 


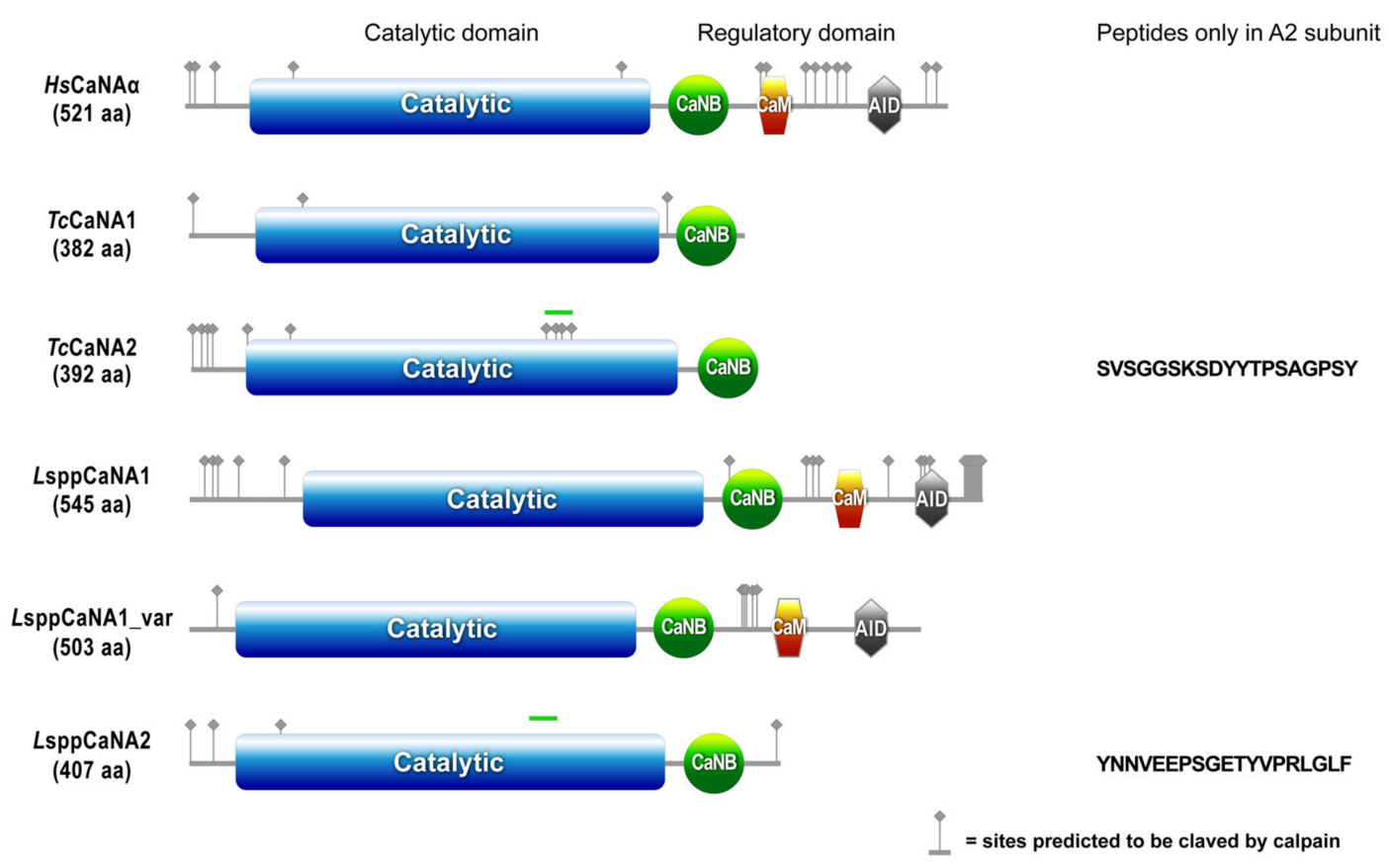

Figure 1. Protein domain architecture in CaNA. In blue is the catalytic phosphatase domain, in green is the CaNB-binding domain, in orange is the domain of interaction with CaM, and in gray is the AID. They are represented by the sites predicted to be cleaved by calpain by GPS-CDD, and the green band on the catalytic domains of TcCaNA2 and LsppCaNA2 corresponds to a peptide not present in the CaNA1 subunits, specified to the right of each subunit. The image was prepared with the MyDomains image creator (Prosite).

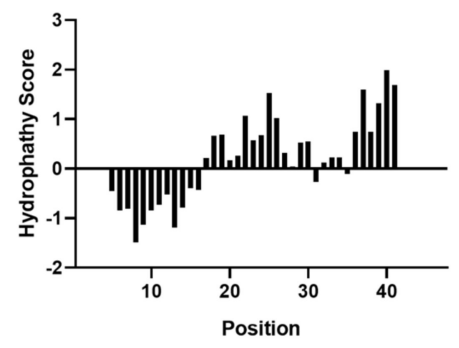

D

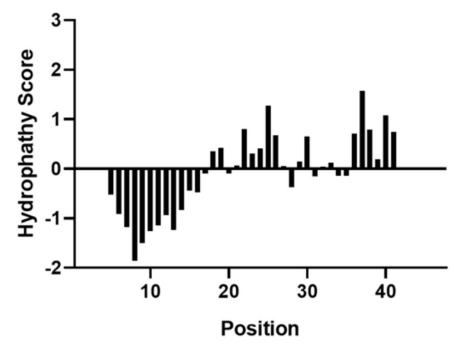

B

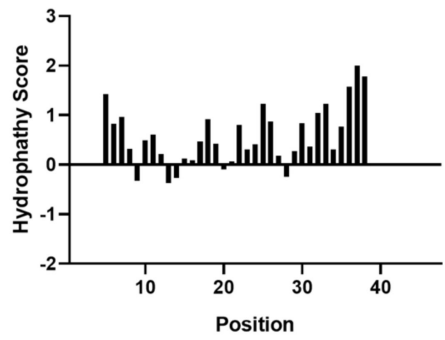

E

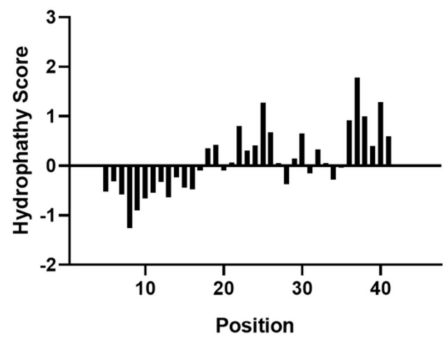

C

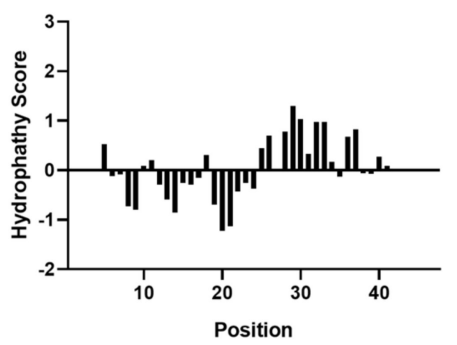

$\mathbf{F}$

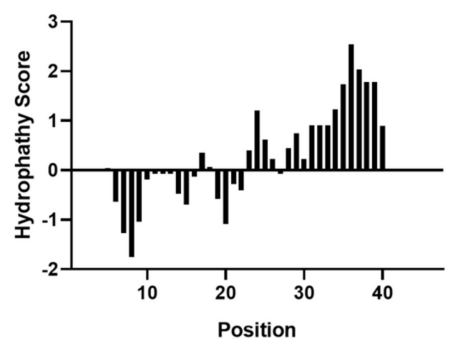

Figure 2. Hydropathy plot for CaNB-BD of CaNA preparated in the Expasy Protscale Website according to the Kyte and Doolittle algorithm. (A) CaNB-BD in $H_{s} \mathrm{CaNA} \alpha$, (B) CaNB-BD in TcCaNA1, (C) CaNB-BD in TcCaNA2, (D) CaNB-BD in LsppCaNA1, (E) CaNB-BD in LsppCaNA1_var, and (F) CaNB-BD in LsppCaNA2. 


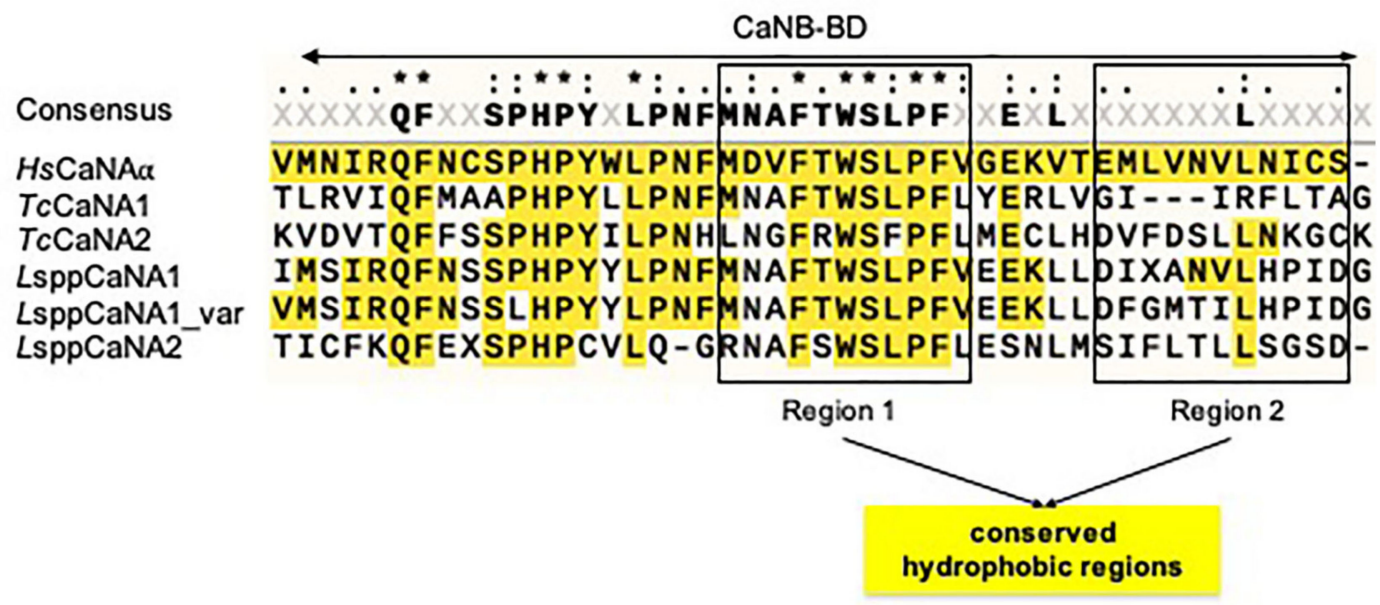

Figure 3. CaNB-BD sequence alignment present in CaNA. The boxes on the left and on the right correspond to the two hydrophobic regions present in CaNB-BD.

In the case of the CaM-BD domain in $H s C a N A \alpha$ (ITSFEEAKGLDRINERMPPRRDA), it is only present in Leishmania in the LsppCaNA1 and LsppCaNA1_var subunits with a level of identity ranging from $42-45 \%$. Regarding the autoinhibitory domain (AID), the level of identity is considerably lower, being 17- 22\% in the LsppCaNA1 and LsppCaNA1_var subunits (Figure 4), lacking the important residues for the autoinhibitory function, D488 and A489 (dotted line box). The analyzed domain structure suggests that, in the case of Leishmania CaNA1, they would have the complete domain structure; however, the role of AID in these subunits is unknown.
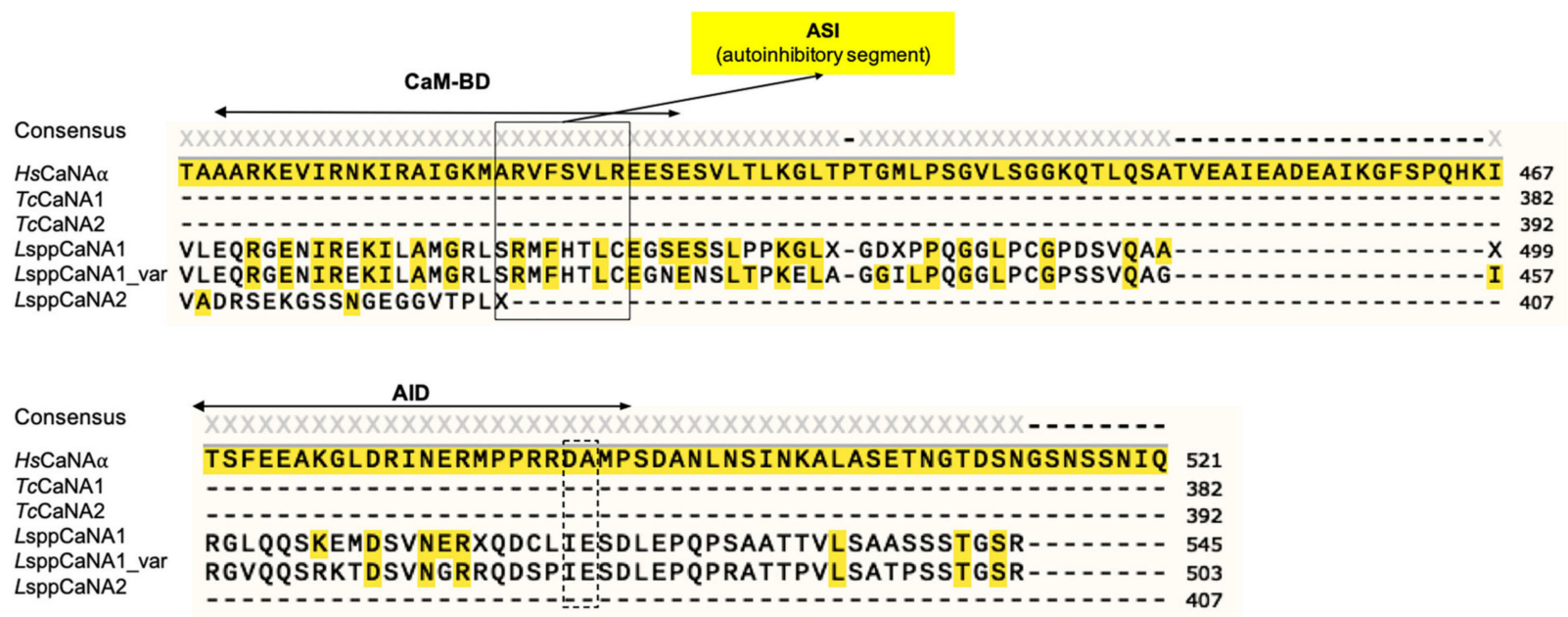

Figure 4. On top: CaM-BD sequence alignment present in CaNA. Underneath: AID sequence alignment present in CaNA.

3.2. The CaM-Binding Domain in Leishmania Spp. Has Greater Potential to Be Regulated by Phosphorylation Than Its Human Ortholog

In total, two serines (position 21 and 27) have the potential to be phosphorylated in the CaM-BD of $\mathrm{HsCaNA}_{\mathrm{S}}$ (Figure 5A), different from that observed in the domain present in Leishmania (LsppCaNA1 and LsppCaNA1_var), presenting a serine and a threonine at positions 17 and 22, respectively (Figure 5B). These sites can be potentially phosphorylated by protein kinase A (PKA) or by an unspecified kinase (unsp) in $H s C a N A \alpha$ and LsppCaNA1 (or also for LsppCaNA1_var), also including in the latter the potential action of PKC or casein kinase II (Table 2). 
A

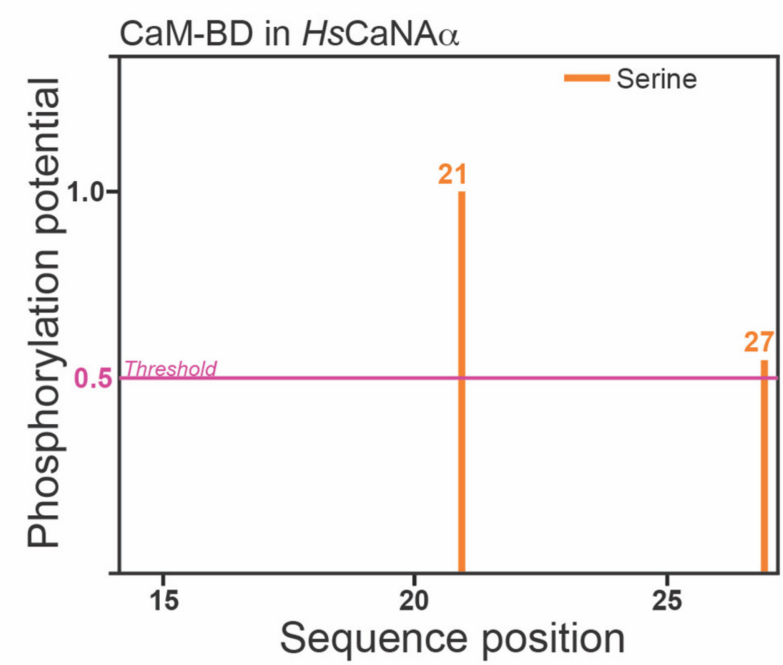

B

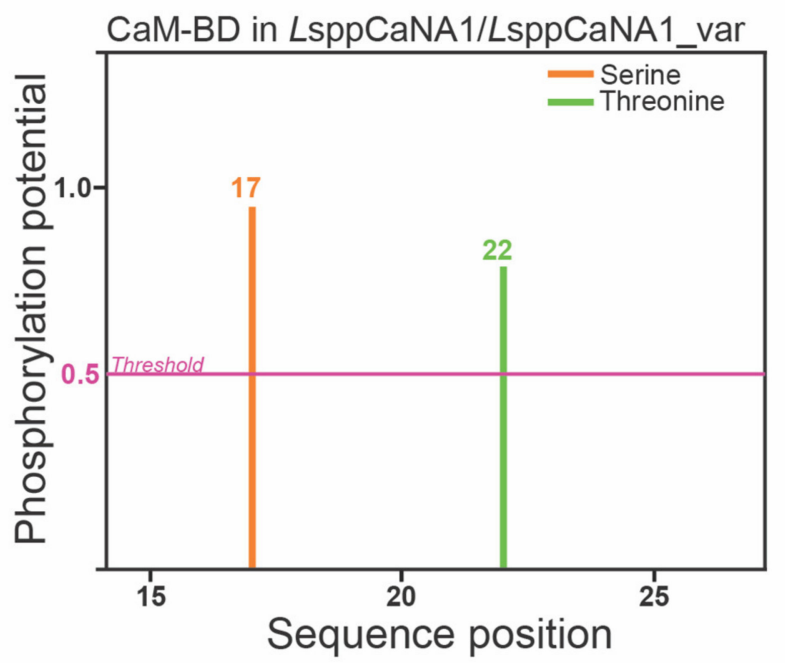

Figure 5. Phosphorylation sites of CaMB-BD in the catalytic subunits predicted by NetPhos 3.1 Server software. All phosphorylation sites presented at the different sequence positions (axis $x$ ) are represented as the phosphorylation potential score (PPS) over the threshold at 0.5 (pink line) at the axis $y$. The predicted phosphorylation sites for CaM-BD in $H s C a N A \alpha$ (A) and in LsppCaNA1 and LsppCaNA1_var (B). Phosphorylation sites in serine (orange) or threonine (green) are shown.

Table 2. Phosphorylation prediction results of CaM-BD in CaNA.

\begin{tabular}{cccccc}
\hline $\boldsymbol{H s C a N A} \boldsymbol{\alpha}$ & \#x & Context & Score & Kinase & Answer \\
\hline $\begin{array}{c}\text { \# Sequence } \\
\text { \# Sequence }\end{array}$ & $21 \mathrm{~S}$ & ARVFSVLRE & 0.974 & unsp & YES \\
$\begin{array}{c}\text { LsppCaNA1 and } \\
\text { LsppCaNA1var }\end{array}$ & $\mathbf{2 7 \mathrm { S }}$ & LREES- & 0.556 & PKA & YES \\
\hline \# Sequence & $17 \mathrm{~S}$ & MGRLSRMFH & 0.956 & unsp & YES \\
\# Sequence & $17 \mathrm{~S}$ & MGRLSRMFH & 0.725 & PKA & YES \\
\# Sequence & $17 \mathrm{~S}$ & MGRLSRMFH & 0.556 & PKC & YES \\
\# Sequence & $22 \mathrm{~T}$ & RMFHTLCEG & 0.766 & Unsp & YES \\
\# Sequence & $22 \mathrm{~T}$ & RMFHTLCEG & 0.517 & CKII & YES \\
\hline
\end{tabular}

3.3. CaN Regulatory Subunits of Obligate Intracellular Trypanosomatids Differ in Their Calcium-Binding Domains from Their Human Counterpart and Myristoylation Potential, but Preserve Some Canonical EF-Loops and the Docking Site for Immunophilin-Immunosuppressive Drug Complexes

As has been described [57], HsCaNB-1 and LsppCaNB (based on the sequences obtained L. major) have four EF hand motifs, while TcCaNB has only three. HsCaNB-1 and LsppCaNB have two low loops and two high affinity loops for $\mathrm{Ca}^{2+}$, while TcCaNB only has one of each type (Figure 6 and Table S1). The complete loops, based on the HsCaNB-1 sequence, meet the condition of having the amino acid organization distributed as follows: DX-[DNS]-\{ILVFYW\}-[DENSTG]-[DNQGHRK]-\{GP\}-[LIVMC]-[DENQSTAGC]-x (2)-[DE] . Moreover, the TcCaNB and LsppCaNB subunits have a hydrophobic groove for the union of the immunophilin-immunosuppressive drug complexes, highlighting the conservation of this region that goes from $\mathrm{M}^{119}$ to $\mathrm{L}^{124}$ (hydrophobic groove), corresponding to HsCaNB-1, being much more hydrophobic in TcCaNB and LsppCaNB than in HsCaNB-1, determined by the grand average of hydropathicity index (GRAVY), which is used to represent the hydrophobicity value of a peptide; positive GRAVY values indicate hydrophobic and negative values mean hydrophilic (Figure 7). 

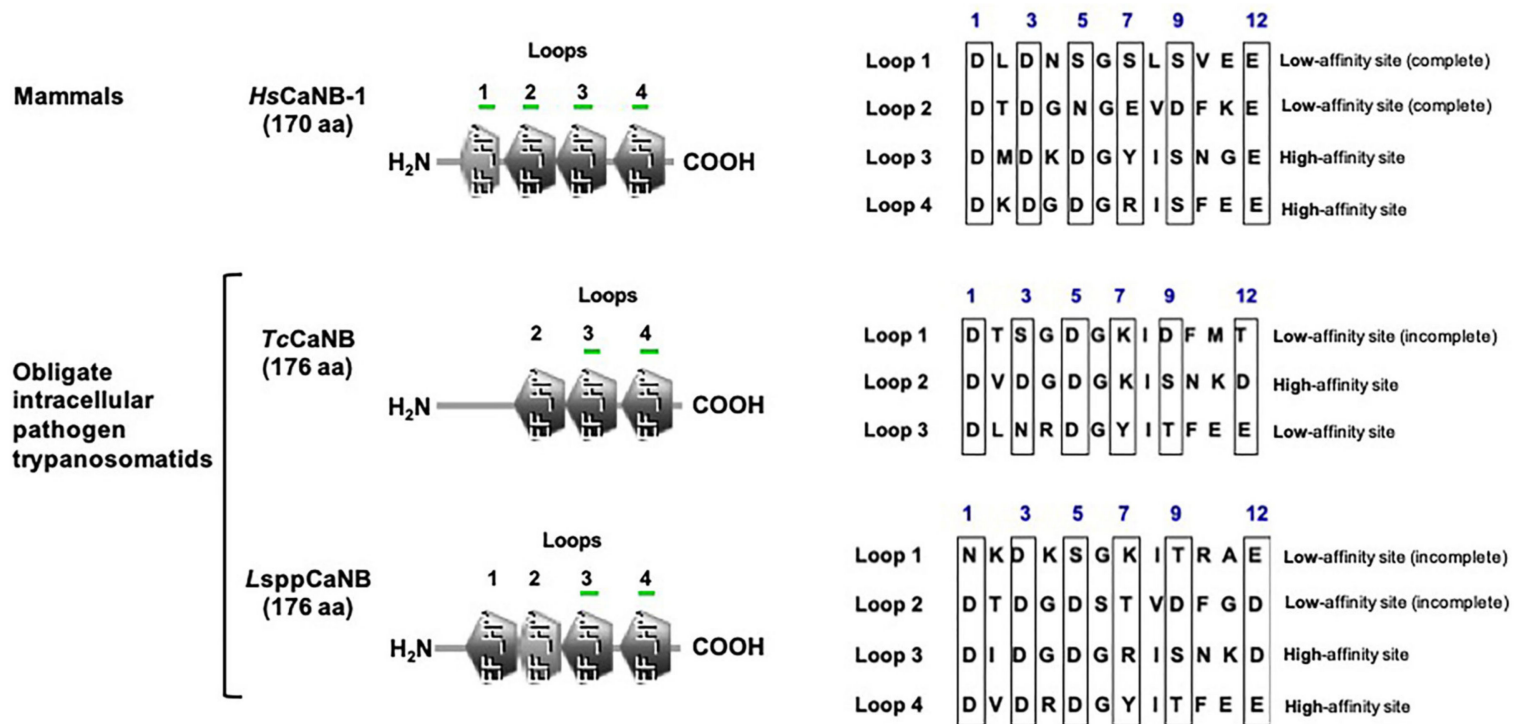

Figure 6. Protein domain architecture in CaNB. Representative scheme of the EF-hand motifs in mammalian CaNB (HsCaNB-1) and in the obligate intracellular trypanosomatids (TcCaNB and LsppCaNB) showing the loops (numbered) containing the calcium affinity binding sites (green underline) with the different amino acids sequences on the right. The blue number over the box represents coordinating sites for $\mathrm{Ca}^{2+}$.

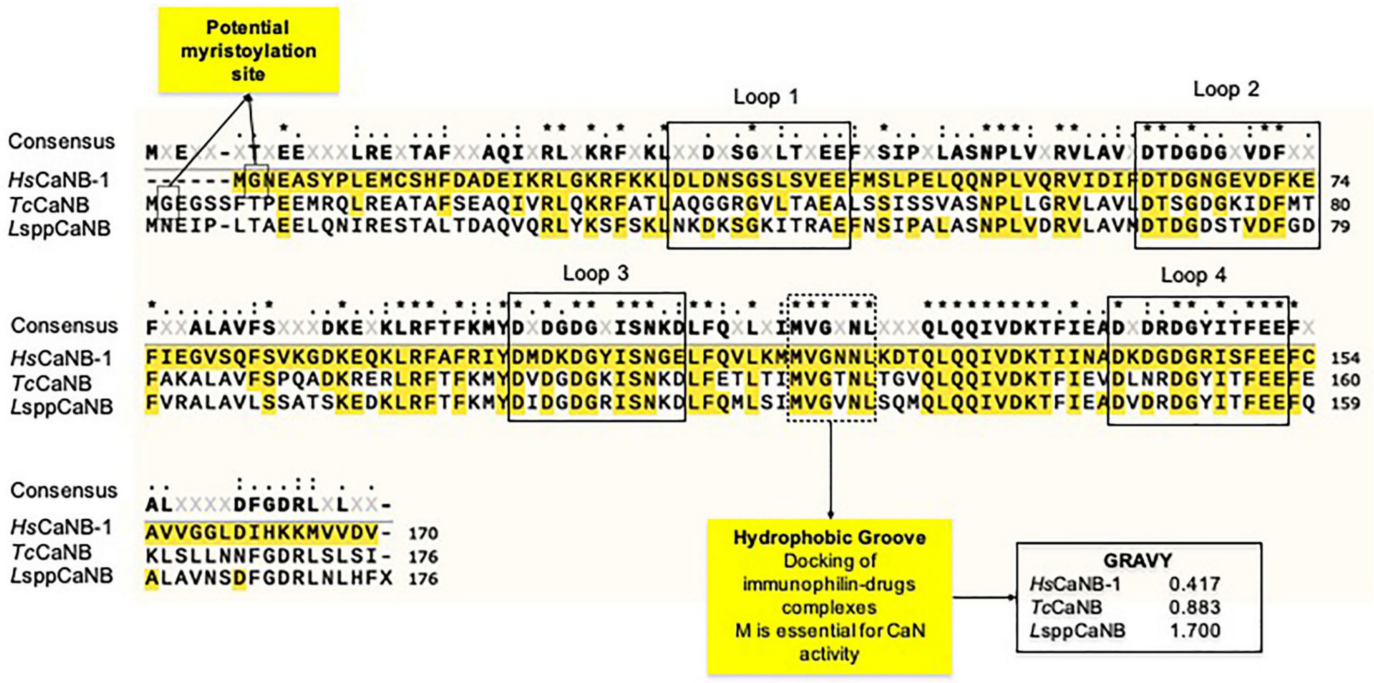

Figure 7. CaNB sequence alignment of the human CaNB (HsCaNB-1) against the different obligate intracellular pathogen trypanosomatids (TcCaNB and LsppCaNB). Conserved residues are in black with * (100\% conservation), in black with: ( $>70 \%$ conservation), and in black with - (between 50 and 70\% conservation). The consensus is shown with a threshold of $50 \%$.

Regarding the potential myristoylation in the intracellular trypanosomatid CaNB subunits, only TcCaNB has a glycine $(G)$ in the second position in the N-term in the same way as the $H_{s} \mathrm{CaNB}-1$ subunit. Curiously, despite the fact that the domain structures between HsCaNB-1 and LsppCaNB are similar to each other, CaNB in Leishmania spp. lacks $\mathrm{G}$ in its $\mathrm{N}$-terminal region to be myristoylated (Figures 6 and 7, Figure S1).

When a Myristoylator (trained to predict myristoylation in the N-terminal end of the amino acid chain) was used to analyze possible myristoylation, only $\mathrm{HsCaNB}-1$ was predicted to be potentially myristoylated with a score of 0.98984294 (high confidence), while TcCaNB was predicted to be non-myristoylated with a score of -0.146144 (Table S2). 
3.4. CaN Regulatory and Catalytic Subunits of Obligate Intracellular and Human Trypanosomatids Would Share the Subcellular Distribution Pattern, with Some Exceptions

The analysis of all the sequences of the catalytic subunits (CaNA) under study using WoLF SPORT suggests a distribution in the cytosolic (cyto), nuclear (nucl), cytosol, and nucleus (cyto_nucl) compartments, and exclusively with a predisposition also at the mitochondrial (mito) level in only the catalytic subunits of T. cruzi and Leishmania spp. (Table 3A), while the HsCaNB-1 subunit has a distribution mainly in the cytosolic (cyto) and cyto_nucl compartments, contrasting with TcCaNB and LsppCaNB having a marked distribution at the nuclear level (nucl) (Table 3B).

Table 3. Predicted subcellular localization of CaNs based on WoLF PSORT.

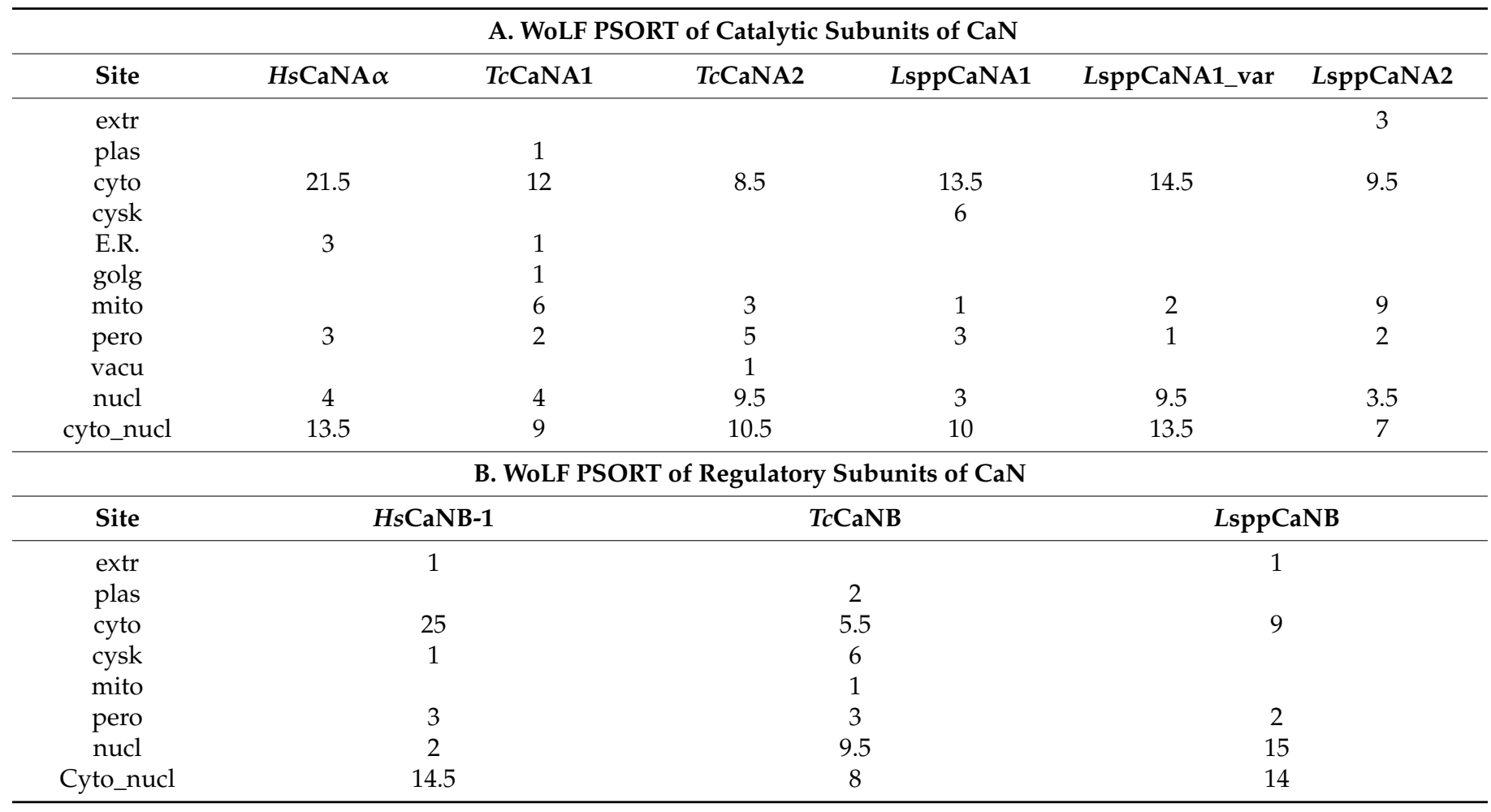

When the analyses were carried out in the CELLO2GO program for the catalytic subunits, the following results were obtained (Figure $8 \mathrm{~A}$ ): $\mathrm{HsCaNA} \alpha$ with $52 \%$ cytoplasmic and 5\% nuclear; TcCaNA1 with 70\% plasmamembrane, $14 \%$ cytoplasmic, and $2 \%$ nuclear; TcCaNA2 with $27 \%$ plasmamembrane, $17 \%$ extracellular and cytoplasmic, and $12 \%$ nuclear; LsppCaNA1 with $51 \%$ plasmamembrane, $21 \%$ cytoplasmic, and $10 \%$ nuclear; LsppCaNA1_var with $48 \%$ plasmamembrane, $18 \%$ cytoplasmic, and $9 \%$ nuclear; and LsppCaNA2 with 57\% plasmamembrane, 25\% extracellular, $7 \%$ cytoplasmic, and 3\% nuclear. In the case of regulatory subunits (Figure 8B), localization of $\mathrm{HsCaNB}-1$ with $39 \%$ cytoplasmic and $54 \%$ nuclear; $\mathrm{TcCaNB}$ with $15 \%$ plasmamembrane, $26 \%$ cytoplasmic, and 3\% nuclear; and LsppCaNB with 5\% plasmamembrane, 49\% cytoplasmic, and 16\% nuclear. Interestingly, only the regulatory subunits TcCaNB and LsppCaNB had 35\% and $8 \%$, respectively, presenting localization at the chloroplast level (Figure 8B). 
A
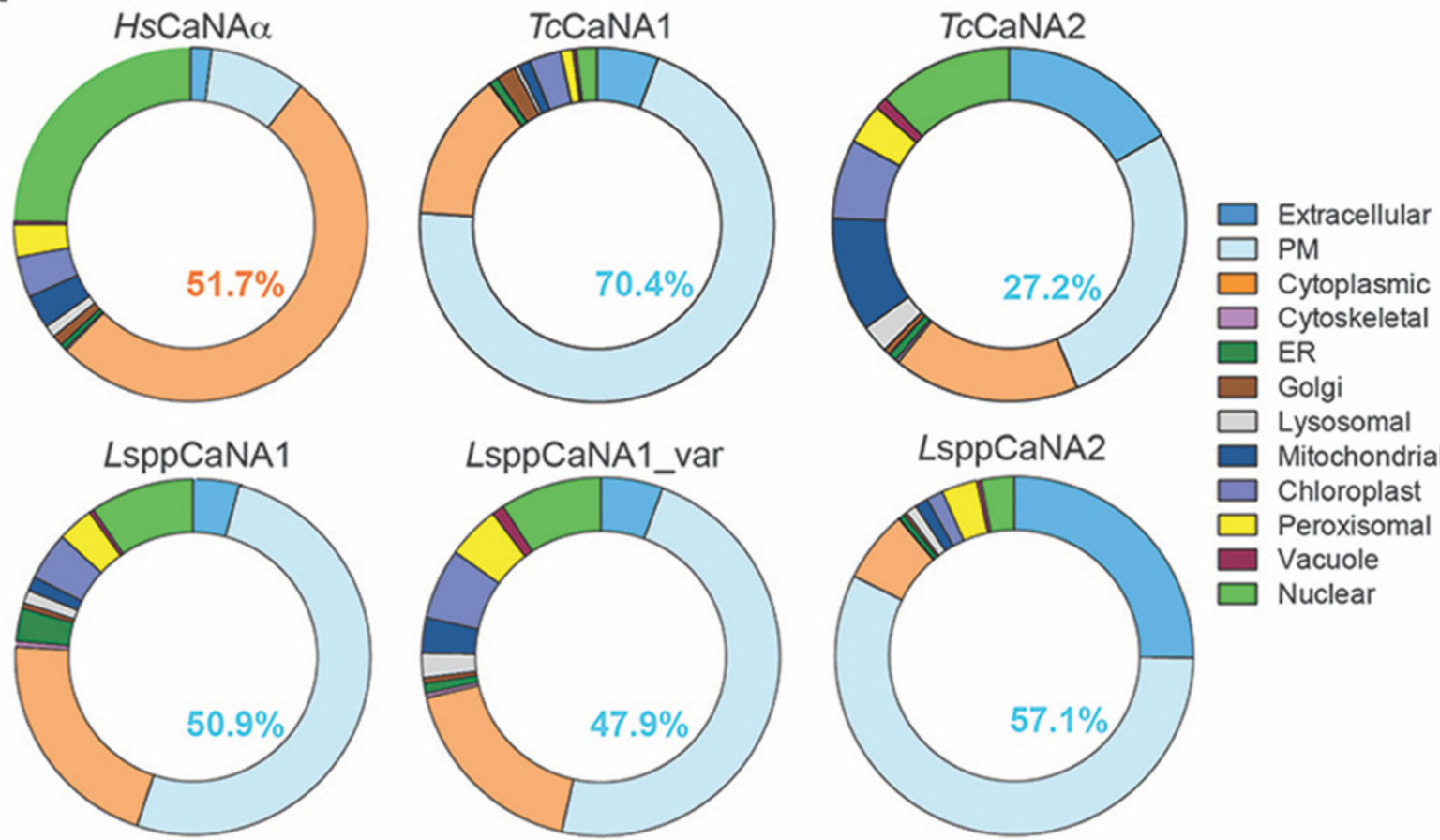

$\square$ Golgi

$\square$ Lysosomal

Chloroplast

$\square$ Peroxisomal

$\square$ Vacuole

$\square$ Nuclear

B
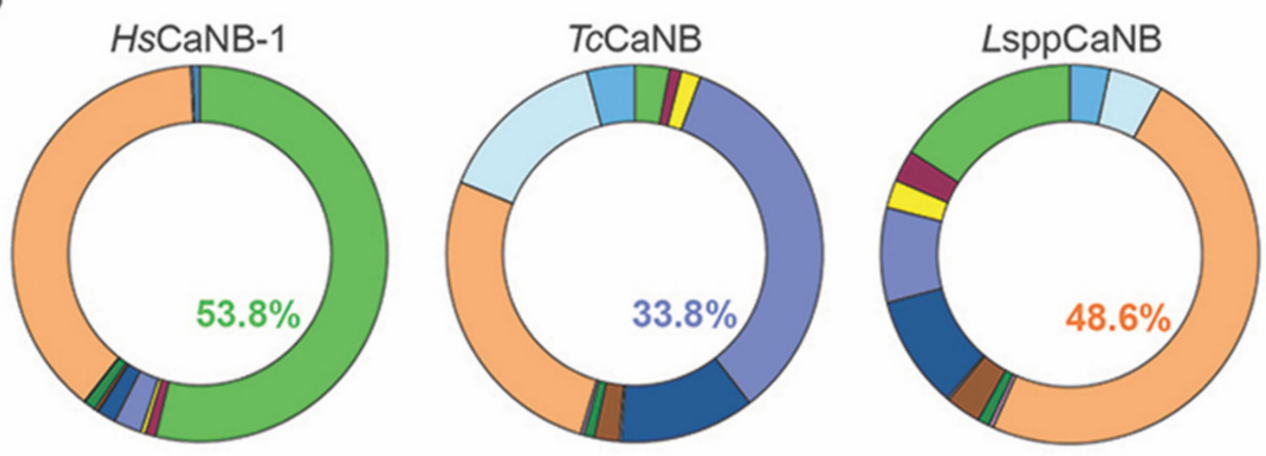

Extracellular

PM

Cytoplasmic

Cytoskeletal

ER

$\square$ Golgi

$\square$ Lysosomal

Mitochondrial

$\square$ Chloroplast

$\square$ Peroxisomal

$\square$ Vacuole

Nuclear

Figure 8. The predicted subcellular localization of CaNA (A) and CaNB (B) using the CELLO2GO web server. The subcellular localizations are represented in ring chart diagrams evaluating the significant terms in the form of their percentage contribution. In each one, the value with the highest probability is shown.

3.5. CaN Regulatory Subunits of Obligate Intracellular Trypanosomatids Interact Only with Their Catalytic Monomer and Related Immunophilins

A PPI network was generated for each of the regulatory subunits; the red nodes represent the proteins of interest and the rest represent those with which it interacts (Figure 9); the score of each node represents the evidence of the interacting proteins. In order to validate the score obtained, a PPI network with $\mathrm{HsCaNB}-1$ was built. Interestingly, for TcCaNB and LmCaNB (and other orthologs in Leishmania, Figure S2), the substrate potential has not been determined, as well as for NFATC1 in H. sapiens. 


\section{A TcCaNB}

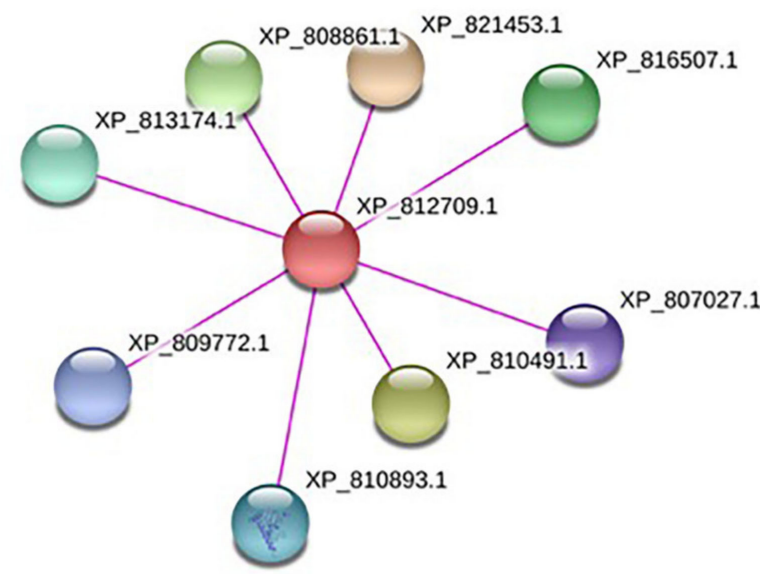

\section{B LmCaNB}

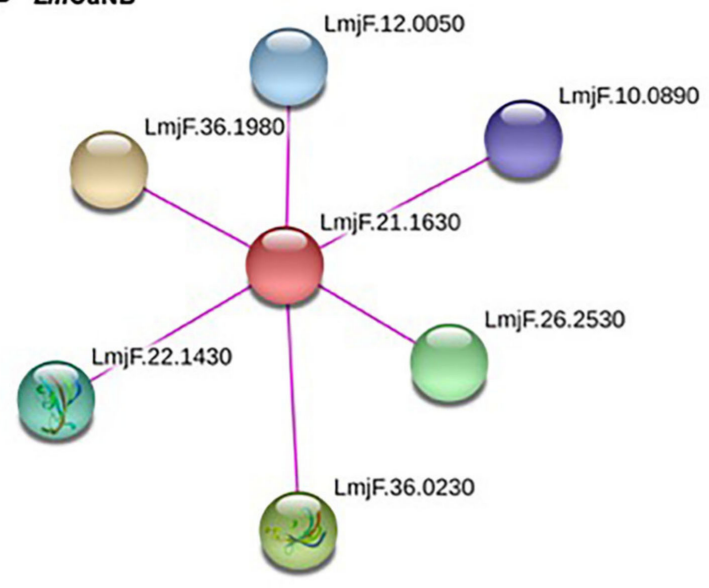

Figure 9. Protein-protein interaction network of the TcCaNB (A) and $L m C a N B(B)$ proteins (STRING V.11.0). The line color indicates the type of interaction evidence (experimentally determined). Parameters: score (high confidence 0.7), sources of interaction used: experimental and databases. In A: XP_812709.1 (calcineurin B subunit, putative), XP_810491.1 (serine/threonine-protein phosphatase), XP_821453.1 (serine/threonine-protein phosphatase), XP_816507.1 (peptidylprolyl isomerase), XP_813174.1 (peptidylprolyl isomerase), XP_810893.1 (peptidylprolyl isomerase), XP_809772.1 (peptidylprolyl isomerase), and XP_807027.1 (peptidylprolyl isomerase); and in B: LmjF.36.1980 (serine/threonine protein phosphatase 2B catalytic subunit A2), LmjF.36.0230 (peptidyl-prolyl cis-trans isomerase, putative), LmjF.26.2530 (serine/threonine protein phosphatase, putative), LmjF.22.1430 (peptidylprolyl isomerase; Fk506-binding protein 1-like protein), LmjF.12.0050 (hypothetical protein, conserved), and LmjF.10.0890 (FKBP-type peptidyl-prolyl cis-trans isomerase).

3.6. CaN Regulatory and Catalytic Subunits of Obligate Intracellular Trypanosomatids Have a Differential Potential to Be Secreted by the Non-Classical Pathway

The predictions obtained for each of the subunits under study suggest that the subunits TcCaNA1, TcCaNB, and LsppCaNA2 with an NN-score of 0.682, 0.637, and 0.718, respectively, are secreted by the non-classical pathway. Only in the case of $\mathrm{HsCaNB}-1$ does it have an NN-score of 0.548 , close to the threshold proposed for mammalian sequences (Table 4).

Table 4. SecretomeP 1. of predictions of CaNAs and CaNBs. Non-classically secreted proteins should obtain an NN-score/SecP score exceeding the threshold, but should not at the same time be predicted to contain a signal peptide.

\begin{tabular}{ccccc}
\hline Name & NN-Score $^{\mathbf{1}}$ & Odds & Weighted by Prior & Warning \\
\hline HsCaNA $\alpha$ & 0.441 & 0.861 & 0.002 & - \\
HsCaNB-1 & 0.548 & 1.252 & 0.003 & - \\
TcCaNA1 & 0.682 & 1.863 & 0.004 & - \\
TcCaNA2 & 0.442 & 0.858 & 0.002 & - \\
TcCaNB & 0.637 & 1.758 & 0.004 & - \\
LsppCaNA1 & 0.528 & 1.094 & 0.002 & - \\
LsppCaNA1_var & 0.477 & 0.926 & 0.002 & - \\
LsppCaNA2 & 0.718 & 2.165 & 0.004 & - \\
LsppCaNB & 0.382 & 0.709 & 0.001 &
\end{tabular}

${ }^{1}$ The recommended thresholds are 0.5 for bacterial sequences and 0.6 for mammalian sequences.

\section{Discussion}

Trypanosomatid parasites have evolved to survive in different environments as their biology has developed, either in vector insects or in mammalian hosts. These different environments involve different parasite forms that could have conditioned the appearance of specific trypanosomatid phosphatases [58]. Regarding CaN, through the analysis of the TriTryp phosphatome, two groups of $\mathrm{CaN}$ were identified; one of them grouped with 
H. sapiens and S. cerevisae, and the second with less similarity to eukaryotic $\mathrm{CaN}$ and with characteristic features of kinetoplastids, and presenting some mutations in its catalytic residues, suggesting that they could be pseudophosphatases [38]. CaN-like activities have been observed in vitro in some of these recombinant A2 subunits [33].

The domain structures of the catalytic subunits of T. cruzi (TcCaNA1 and TcCaNA2), in which each one of them presents the CaNB-BD and catalytic domain, have already been identified and characterized [32,33,37]. On the other hand, in Leishmania, the same analysis has determined that it possesses the four characteristic domains of $\mathrm{CaN}[37,59]$. In the present work, we seek to highlight the differences at the level of the primary structure of the subunits under study and the proposed regulatory mechanisms. In this regard, mammalian catalytic isoforms have a molecular mass (MW) ranging from 57 to $59 \mathrm{kDa}$, whereas lower eukaryotes vary from 57 to $71 \mathrm{kDa}$ [17]. In addition, the $\mathrm{pI}$ of the TcCaNA2 and LsppCaNA2 subunits ( 8.13 and 6.37 , respectively) deviate considerably from the range of $\mathrm{pI}$ observed for mammalian isoforms. In the case of the isoform $\alpha(\mathrm{pI}=5.6-5.8), \beta 1(\mathrm{pI}=5.3)$, $\beta 2(\mathrm{pI}=5.6-5.8)$, however, the isoform $\gamma(\mathrm{pI}=7.1)$ specific to the testis possesses a higher pI [60]. The latter suggests a differential subcellular distribution between the $\mathrm{CaN}$ subunits of these protozoa by virtue of pI [61,62].

A transcendent regulatory mechanism for the action of CaNA is cleavage by calpain. Curiously, calpains and calcineurins share the same subcellular distributions and exhibit equally high levels of activity after many of the same types of insults, thus $\mathrm{Ca}^{2+}$ and $\mathrm{CaN}$-sensitive protease are considered common effectors of $\mathrm{Ca}^{2+}$-induced dysfunctions and degenerations [63]. Calpain is capable of cleaving CaNA directly and increasing its phosphatase activity [64], generating more active 57, 48, and $45 \mathrm{kDa}$ products in excitotoxic neurodegeneration models [65]. From the potential calpain cleaved sites analyzed by GPSCDD in the CaNA subunits of T. cruzi and Leishmania spp., only TcCaNA1 and LsppCaNA1 possess a cleavage site located between the catalytic domain and the regulatory domain of $\mathrm{CaN}$, which could upregulate $\mathrm{CaN}$ phosphatase activity by removing the regulatory domain [66] or parts of it [67], while the other sites could have other regulatory effects or impair CaN activity if they are located in the catalytic domain of CaNA. On the other hand, the insertion 243-VSGGSGSDYYTPSAGPSYGS-262 present in TcCaNA2, but not in TcCaNA1, has 4 of the 12 potential sites to be cleaved by calpain [33], while the insertion 235-YNNVEEPSGETYVPRLGLF-253 in LsppCaNA2 does not present any possibility of being cleaved. The regulation exerted by calpains in the biological cycle of T. cruzi has been studied through the use of inhibitors such as MDL28170, which stops the growth of epimastigote forms [68], in the same way as the role attributed to the TcCaNA2 in epimastigote proliferation [33]. Moreover, using the inhibitor MDL28170, it was shown that it decreases the viability of blood trypomastigotes and affects metacyclogenesis as well as the adherence of the parasite to the luminal surface of the triatomine gut $[69,70]$. It also inhibits the growth and viability of promastigotes of L. amazonensis [71]. The involvement of these enzymes is so great that there is evidence to suggest trypanosomal calpains as good drug targets [72]. Despite this, it is important to consider that inhibitors such as MDL28170 also act on host calpains, which is why studies are required to determine how pseudoproteolytic trypanosomal calpains function and how calpain inhibitors act against them [73]. This reinforces the important role of molecules associated with $\mathrm{Ca}^{2+}$, such as calpains and $\mathrm{CaN}$, in basic cellular functions of the life cycle of T. cruzi and Leishmania spp.

It has been described that CaNB-BD in the catalytic subunit $\alpha \delta$ of rat brain has four hydrophobic amino acid residues $\left(\mathrm{Val}^{349}-\mathrm{Phe}^{350}\right.$ and $\mathrm{Phe}^{356}-\mathrm{Val}^{357}$ ), which are essential for the interaction between the catalytic subunit and the calcineurin regulatory subunit [20]. This configuration allows two hydrophobic peaks to be generated in the CaNB-BD. In the case of CaNB-BD of the CaNA subunits of T. cruzi and Leishmania, the $\mathrm{Val}^{349}$ residue of the $H s \mathrm{CaNA} \alpha$ subunit is not present in their corresponding protozoan orthologs. This makes the hydrophobic profile of the surrounding residues different, which suggests that the degree of differential hydrophobicity of CaNB-BD present in the CaNA of T. cruzi and 
Leishmania conditions the interaction of the invariant CaNB subunit with the CaNA1 or CaNA2 subunits in the conformation of the heterodimers.

The diversity of CaNA in Leishmania that present or not the CaM-BD may establish a differential role in the cellular processes of the parasite. Interestingly, a calciumindependent, but $\mathrm{CaM}-\mathrm{CaN}$-dependent signaling pathway has been proposed in regulating the inversion of the flagellar wave, acting antagonistically to the cAMP-dependent pathway, so both of these pathways could establish an equilibrium between flagelar or ciliary churning waveforms, allowing appropriate motility and responses of the parasite in its environment, crucial for its viability, survival, and infectivity [35].

Unlike the CaM-BD present in $H s C a N A \alpha$, which has the following sequence: ARKEVIRNKIRAIGKMARVFSVLREES, with conserved residues with positive charge (in bold) and potential kinase phosphorylation site (underlined) [21], which is recognized in the ARVFSVLRE context to be phosphorylated in S by an unknown kinase and in LREES by PKA and as well as in brain CaNA [74], the CaM-BD in LsppCaNA1 and LsppCaNA1_var have an identity of $50 \%$ and $53 \%$, respectively, with only four residues with a positive charge; however, they have a greater potential to be targeted for phosphorylation by kinases such as PKA and PKC, either in serine or threonine. It may be a regulatory mechanism of the CaM interaction of the parasite towards the LsppCaNA1 and LsppCaNA1_var subunits, as has been described for other CaM-binding proteins [75,76].

In relation to the AID present in $H_{s} \mathrm{CaNA} \alpha$, it has been proposed as a pseudosubstrate exerting an action mechanism that blocks the active $\mathrm{CaN}$ site [24], together with evidence of the existence of additional autoinhibitory elements between CaM-BD and AID [77]. In fact, an autoinhibitory element present in the $\alpha$ and $\beta$ isoforms of human CaNA called ASI (autoinhibitory segment) has been described, having the sequence ${ }^{416}$ ARVFSVLR $^{423}$; importantly, it interacts with a hydrophobic groove formed at the junction of the CaNA and CaNB subunits [78]. In LsppCaNA1 and LsppCaNA1_var, the amino acid sequence of this region was assigned as SRMFHTLC. This element could have a similar role in Leishmania spp., as the ASI potential presents three nonpolar residues (M, F, and L) of the total of five present in the ASI in the isoforms $\alpha$ and $\beta$ of human CaNA, and the basic character of the $R$ residue is present in both sequences.

In the case of CaNB, the domains' architecture possessed by CaNB of these trypanosomatids is different, with three EF hand motifs for T. cruzi and four for Leishmania spp. [32,37]. These structural characteristics suggest a differential activation mechanism for their corresponding catalytic subunits, which could be closely related to the associated functional roles, such as invasion, proliferation, response to stress, and motility, among others [32-35]. Interestingly, the analysis of the domain architecture in Trypanosoma rangeli, a non-virulent trypanosome for mammals, suggests the presence of four EF-hand motifs with a potential role in the growth of epimastigotes, and of these four EF-hand motifs, only three fulfill the expected pattern of amino acid residues involved in coordinating $\mathrm{Ca}^{2+}$ [79]. In the case of $\mathrm{HsCaNB}_{\mathrm{C}}$, the analysis using the Prosite program attributes a lower score to the EH-hand motives towards $\mathrm{N}$-term, while these are higher towards C-term, according to what has already been evidenced [80]. Thus, CaNB in these protozoa, unlike its counterparts in mammals and fungi that have four complete EF-hand motifs, has only two complete typical EF-hands, presenting the following "motif signature": Dx-[DNS]-\{ILVFYW\}-[DENSTG]-[DNQGHRK]-\{GP\}-[LIVMC]-[DENQSTAGC]-x (2)- [DE][LIVMFYW] (http:/ / prosite.expasy.org/cgi-bin/prosite/ nicedoc.pl?PS00018 (accessed on 30 May 2020)), establishing a conformation pattern of one or two damaged or incomplete EF-hands in the case of TcCaNB [32,37] and LsppCaNB, respectively, followed by two complete functionals.

The conformation pattern of the EF hand motifs (the first damaged and odd followed by two functional ones) of TcCaNB is also observed in oncomodulin and parvalbumin, proteins that are phylogenetically related to CaNB [81]. Therefore, these low affinity sites in the CaNB subunit of these protozoa would have a conformational role towards the CaNA subunits, as has been described for rat CaNB; high affinity sites are always 
saturated with $\mathrm{Ca}^{2+}$, while the low affinity sites are regulated by the concentration of $\mathrm{Ca}^{2+}$. Thus, the binding of $\mathrm{Ca}^{2+}$ to the low affinity sites affects the conformation of $\mathrm{CaNB}$ and, when associated with CaNA, induces a conformational change in the regulatory domain, which leads to the exposure of the binding domain with CaM. This conformational change, necessary for the partial activation of the enzyme in the absence of $\mathrm{CaM}$, allows it to become fully active when associated with CaM $[80,82]$.

Through the generation of mutants in the $\mathrm{E}$ (acid) residue at position 12 of each loop that binds $\mathrm{Ca}^{2+}$ to $\mathrm{L}$ (basic) of $\mathrm{HsCaNB}$, the individual role of each $\mathrm{EF}$ hand motif was determined (by eliminating the $\mathrm{Ca}^{2+}$ binding capacity in each of them), showing that those mutations in the EF-hand motifs 1 and 2 (towards $\mathrm{N}$-term) suffered variations in their electrophoretic mobility depending on the presence or absence of $\mathrm{Ca}^{2+}$. Meanwhile, in those with mutations in EF-hand 3 and 4 motifs (towards C-term), no differences were observed in the electrophoretic pattern, suggesting that $\mathrm{Ca}^{2+}$ binding in EF-hand motifs 1 and 2 varies according to their concentration, dynamically modulating the enzymatic function, while EF-hand 3 and 4 would always be saturated with $\mathrm{Ca}^{2+}$, fulfilling a structural role [80]. Moreover, ${ }^{45} \mathrm{Ca}^{2+}$ exchange is faster in EF-hand 3 than EF-hand 4 mutated, indicating that these sites are not equivalent and that the effects on heterodimer formation are greater in the EF-hand 3; this could explain the differences observed in the two functional EF-hands of TcCaNB, establishing a structural role for EF-hand 3 and a conformational role for EF-hand 4 , and for LsppCaNB, a structural role for EF-hand 3 and 4 and a conformational role for EF-hand 1 and 2.

With respect to the subcellular distribution of $\mathrm{CaN}$, in mammals, it associates predominantly in the cytoplasm and in the synaptosomal cytosol [83]. It has also been associated with synthetic vesicles, suggesting that $\mathrm{CaN}$ binds unilamellar vesicles, this being a $\mathrm{Ca}^{2+}$ dependent mechanism [84]. Regarding the NFAT activation pathway, it is shown that $\mathrm{Ca}^{2+}$ induces an association between CaN and NFAT, which results in the colocalization of both molecules in the nucleus [85]. It is important to mention the location and differential expression of isoforms of the CaNA, as is the case of neuronal isoforms $\alpha$ and $\beta$. Isoform $\alpha$ was visualized at the nuclear level, while isoform $\beta$ was found in the cytoplasm of a wide variety of cells of the central nervous system (CNS) [86]. These results suggest that each isoform would present different sites of action in the neurons of the CNS and that this phenomenon has been conserved during evolution. A clear example of this differential functionality is that observed in mice lacking the isoform $\beta$, in which alterations are generated in the function and development on immune system [87], while the mice lacking the $\alpha$ isoform suffer kidney dysfunction [88]. Therefore, it is possible to affirm that CaN isoforms can be differentially expressed and/or the activity of each one of them can be differentially regulated, allowing their specific function.

Studies in yeast have shown that $\mathrm{CaN}$ dephosphorylates the transcription factor Crz1p in vitro and that its location is displaced from the cytosol towards the nucleus subsequent to the in vivo activation of $\mathrm{CaN}$, demonstrating that $\mathrm{CaN}$ regulates the phosphorylation and localization of Crzlp, and identifies Crzlp as the first CaN substrate protein [30]. Furthermore, their observations reveal that the mechanism by which CaN regulates gene expression in yeast and mammalian cells is strikingly similar [30]. Curiously, in parasitic protists, they do not appear to possess yeast Crz1 or mammalian NFAT orthologs in their genomes and lack transcription factors [31], suggesting that the CaN cascade may function in ways other than factor-mediated regulatory mechanisms of transcription that control the virulence of parasitic protists owing to the considerable evolutionary distance compared with fungi [12]. However, some CaN targets have been proposed for Plasmodium falciparum including HSP90, actin-1, and phosphoglycerate kinase [89]; in T. cruzi, CaN would act during the process of cell invasion on protein targets of high molecular mass [32], while in Leishmania spp., it has not been addressed.

Regarding the characterization of some $\mathrm{CaN}$ subunits in kinetoplastids, this has been described in Leishmania spp. and in T. cruzi [58], and in T. brucei, there is information on the cellular localization by microscopy of the CaN subunits: for TbCaNA1 (Tb927.9.1540) in 
cytoplasm and flagellar cytoplasm; for TbCaNA2 (Tb927.10.6460) in cytoplasm, flagellar cytoplasm, and nuclear lumen; and for TbCaNB (ID Tb927.10.370) in endocytic compartmen and cytoplasm (see TrypTag.org database). In the case of Leishmania donovani, CaN has a cytosolic localization in promastigote forms that depends exclusively on $\mathrm{Ca}^{2+}$ and $\mathrm{CaM}$ for its activity, which was biochemically evidenced [90]. In T. cruzi, the TcCaNA1 subunit presents an evidently nuclear cellular localization in epimastigotes and amastigotes [37], and TcCaNA2 presents a cytosolic localization in epimastigotes [33], and in the case of $T c \mathrm{CaNB}$, a predominant localization was observed to be cytosolic with some accumulation in the kinetoplast (data not shown). These analyses support a probable co-distribution of the TcCaNA2 and TcCaNB subunits.

Through the in silico analysis of the amino acid sequences of the CaN subunits in T. cruzi and Leishmania spp., in the CELLO2GO tools [52] and WoLF PSORT [51], we sought to predict subcellular localization. Oddly, all CaN catalytic subunits of T. cruzi and Leishmania spp. have a marked predisposition for plasma membrane over cytoplasmic localization and, in the case of CaNA2, a strong extracellular component. These characteristics suggest that these phosphatases may be secreted and behave as virulence factors acting synergistically or independently in infected cells [91-93]. In the case of the TcCaNB, the analyses suggest that a localization in the chloroplast may be due to its proximity to the calcineurin B-like proteins present in plants, which have substitutions in their first EF-hand motif that seem to be unable to bind $\mathrm{Ca}^{2+}[94]$ with the second incomplete EF-hand motif and the third and fourth complete motifs analyzed in Prosite (Figure S3).

Studies have shown that several extracellular proteins can be exported without possessing a classical N-terminal signal peptide, such as FGF-1, FGF-2, IL-1, and galectins [53]. In the case of T. cruzi and Leishmania, studies indicate that they produce ectosomes, exosomes, and other soluble proteins not associated with vesicles from which they are released to deliver cargo on the host cells [95-99]. Studies on Leishmania spp. suggest that the exosome pathway is an unconventional protein secretion mechanism as most of the exosome proteins do not contain a predicted signal peptide [95]. The analyses carried out give a secretion potential through the non-classical pathway to TcCaNA1, TcCaNB, and LsppCaNA2 (NN-score > 0.6); in the case of LsppCaNA1 and $\mathrm{HsCaNB}$, they have a close score, which argues in favor of the potential of these molecules to modulate the host cell, as in the case of some phosphatases described in T. cruzi [100]; particularly, the T. cruzi secretome has revealed the presence of $\mathrm{Ca}^{2+}$ binding proteins such as calreticulin (gi | 322823951) involved in host-parasite interaction, a calcium-binding protein (gi | 487896), calmodulin (gi | 10386) involved in cell signaling, and a calpain-type cysteine peptidase (gi I 322830271) whose role is associated with proteolysis [97], with a characteristic of these proteins being the presence of EF-hand motifs. One of these proteins that has acquired a preponderant role as a modulator of the functions of the extracellular microenvironment is calreticulin (TCCRT), mediating the infectivity of the parasite to inhibit complement; it is also antiangiogenic and inhibits tumor development in vivo [101].

Several data have shown similar host responses against Leishmania and tumor progression $[102,103]$. Both parasite infection and tumor cells have to deal with the immune response to proliferate and survive, showing the importance of controlling immunological response favoring both models [104,105]. However, target-signaling mechanisms could function in opposite directions when activated by its heterologous molecules [106]. In this scenario, the release of an active $\mathrm{CaN}$ could participate by blocking or activating signaling pathways at far distances to promote resistance or susceptibility. This is not uncommon, as the discovery of the role of extracellular vesicles by transporting active molecules [107] shows a sophisticated and broad way of communication for parasites [9] and tumor cells [105]. Recently, $\mathrm{HsCaNB}_{\mathrm{C}}$ has acquired interest as it has been attributed anti-tumor roles, categorized as immunity-mediated killing (extracellular role) and direct pro-apoptotic killing (intracellular role) [108]. In their extracellular role, it was determined that $H_{s} \mathrm{CaNB}$ is a ligand of the $\alpha \mathrm{M}$ integrin, which corresponds to a subunit of the heterodimeric integrin $\alpha \mathrm{M} \beta 2$, a receptor expressed mainly on the surface of innate 
immunity cells (macrophages, monocytes, neutrophils, and NK cells), suggesting that the levels of $\mathrm{HsCaNB}$ in the serum are important for the maintenance of the innate immune response and the immune surveillance of cancer, through the activation of the monocytemacrophage axis [109]. It was then shown that exogenous HsCaNB uptake depends on the TLR4/MD2/CD14 receptor complex, indicating a second membrane receptor (TLR4) plays a critical role in innate immunity and its connection with adaptive immunity [110]. Recently, recombinant $H_{s} \mathrm{CaNB}$ (rhCNB) has been implicated in the inhibition of the proliferation of gastric cancer cells and hepatomas, through the induction of apoptosis and arrest of the cell cycle, as rhCNB promotes the expression of p53 and decreases the expression of cyclin B1 and cyclin-dependent kinase $1(\mathrm{Cdk} 1)$, contributing to arrest in G2/M [111]. Through the generation of rhCNB truncates, the domain that mediates internalization called Trun3 was identified, which is captured by tumor cells and directed to tumors with almost the same efficiency as untruncated rhCNB, thus being a perfect antitumor candidate [112]. These studies suggest that these trypanosomatid CaNB subunits (particularly TcCaNB owing to their potential secretion) could play a role as mediators of the host immune response (among other potential mechanisms of action yet to be elucidated) during parasite infection and tumor formation.

With regard to the protein-protein interactions determined for TcCaNB and $L m C a N B$ based on the parameters used, the predictions establish contact between the CaNB subunits and the CaNA subunits, and between the CaNB subunits and peptidylpropyl isomerases. In particular, in the case of TcCaNB, the predicted functional partners XP_810491.1 (allele of TcCLB.508413.40) and XP_808861.1 (allele of TcCLB.510755.138) are putative sequences that have a 98-99\% identity with TcCaNA1 [37], while STRING does not predict the interaction between TcCaNB and TcCaNA2, as evidenced in vitro by far-Wester blotting [33]. Nevertheless, the other predicted functional partners were proteins with a peptidylprolil isomerase function FKBP type, among them XP_810893 described as TcMIP, which is homologous to other FK506 binding proteins [113], behaving as a virulence factor that is secreted only by trypomastigotes [114], and those parasites exposed to the cyclophilin TcCyP19-trialisin complex show a greater capacity to invade the host cell through activation the parasite CaN pathway [115]. Curiously, the localization of TcCaNB is mainly in the vicinity of the flagellar pocket (unpublished results) in infective and replicative forms, strongly suggesting that these T. cruzi proteins are secreted by events restricted to the flagellar pocket [116] such as the case of cruzipain [117].

Finally, the search for a new potential target as a parasitic CaN should have the objective of developing drugs that act specifically on pathogens while being non-immunosuppressive [12] Another important aspect is that the drugs act directly on CaN, to avoid the effects of CsA and FK-506 on the peptidyl-prolyl-cis-trans isomerase activity of their related immunophilins (as mediators of the interaction with $\mathrm{CaN}$ ), which is why the structure-based design of a highly selective inhibitor directed to the catalytic site of CaNA or on CaNB [118,119] are strategies that could specifically target T. cruzi and Leishmania.

\section{Conclusions}

In this work, it was possible to establish that the domain structure is diverse among the catalytic subunits of CaN of intracellular trypanosomatids, thus establishing potential different post-translational regulation mechanisms observed in the analysis of cleavage by calpains, or by the phosphorylation patterns in the regulatory domains of the catalytic subunits, particularly in the A1 subunits in Leishmania (LsppCaNA1 and LsppCaNA1_var). In the case of regulatory subunits, the domain structure is different, with LsppCaNB being more similar to the human regulatory subunit (HsCaNB-1) than to TcCaNB, although the binding affinity for $\mathrm{Ca}^{2+}$ is conserved between TcCaNB and LsppCaNB. On the other hand, although the coupling sites to the immunophilin-immunosuppressive drug complexes are present in TcCaNB and LsppCaNB, the myristoylation potential is only found in HsCaNB-1.

Regarding the analysis of the subcellular distribution, the catalytic subunits of T. cruzi and Leishmania spp. preferentially (more than 50\%) present a localization in the plasma 
membrane (with the exception of TcCaNA2a with only 27.2\%), different from $H_{s} \mathrm{CaNA} \alpha$, which is predominantly cytoplasmic $(51.7 \%)$. In the case of regulatory subunits, the distribution was more heterogeneous, being more associated with chloroplast and cytoplasmic for $L$ sppCaNB (33.8\% and $26.5 \%$, respectively) and preferentially in cytoplasm (48.6\%) for $\mathrm{TcCaNB}$, when comparing the nuclear/cytoplasmic localization of $\mathrm{HsCaNB}-1$ (53.8\% and $38.6 \%$, respectively).

Besides the catalytic subunits, the interaction with molecules with peptidylprolyl isomerase activity, which is typical of cyclophilins and FKBPs, is confirmed in the analysis of $T c C a N B$ and $L s p p C a N B$ potential interactors. Concerning the potential secretion, TcCaNA1, $T c \mathrm{CaNB}$, and LsppCaNA2 can be secreted by the non-classical pathway, suggesting new extracellular roles for these protein phosphatases.

On the basis of these in silico data, differential $\mathrm{CaN}$ regulation mechanisms are established between these protozoa and its human counterpart, complementing the knowledge of this phosphatase, promoting the development of new potential pharmacological targets to combat neglected diseases caused by these intracellular trypanosomatids.

Supplementary Materials: The following are available online at https:/ /www.mdpi.com/article/10 $.3390 /$ biom11091322/s1, Supplementary file 1: Amino acid sequences of the catalytic and regulatory subunits of Leishmania spp. used in the present study; Table S1: ScanProsite Score hits by 1 profile (pattern PS00018 *); Table S2: Myristoylator results; Figure S1: BLAST protein comparison of HsCaNB1 with TcCaNB (A) and HsCaNB-1 with LsppCaNB (B) using Blast 2 sequences interface; Figure S2: Protein-protein interaction network of the Leishmania infantum (LiCaNB) and Leishmania panamensis ( $\mathrm{p} \mathrm{CaNB}$ ) CaNB proteins (STRING V.11.0); Figure S3: Protein domain architecture of calcineurin B-like of Arabidopsis thaliana (AtCBL1).

Author Contributions: Conceptualization, P.R.O., M.C., and J.E.A.; methodology, P.R.O.; software, P.R.O.; validation, P.R.O., M.C., and J.E.A.; formal analysis, P.R.O. and M.S.-R.; investigation, P.R.O. and M.S.-R.; resources, P.R.O. and J.E.A.; data curation, P.R.O.; writing — original draft preparation, P.R.O., M.C., and J.E.A.; writing - review and editing, P.R.O., M.C., and J.E.A.; visualization, P.R.O., M.S.-R., and M.C.; supervision, J.E.A.; project administration, P.R.O. and J.E.A.; funding acquisition, P.R.O., M.C., and J.E.A. All authors have read and agreed to the published version of the manuscript.

Funding: This work was funded by MINEDUC-UA grant ANT1856, FONDECYT-Chile grant 1051045, PIA grant CeBiB FB-0001, Universidad de Antofagasta (VRIIP); J.E.A and P.R.O received research support by Semillero Grant 5301 and Áreas de Escaso Desarrollo grant AED 17-18-02. P.R.O was supported by Programa de Iniciación en Investigación para Investigadores Jóvenes de la Universidad de Antofagasta (DE446-2015). M.S.-R. was a research fellow of CONICYT 21150528. M.C. received research support by Brazilian sources from the São Paulo Research FoundationFAPESP (Grant number: 2012/24105-3, Grant \#2020/13562-0), the National Council for Scientific and Technological Development (CNPq; Grant number 443816/2014-0), and the Coordination for the Improvement of Higher Education Personnel (CAPES; Finance Code \#001). M.C. also coordinates the Research Collaboration Fund "Discovery of New Antiparasitic Agents" from Union Iberoamericana de Universidades (UIU), Proposal 1054, 1st and 2nd Research Collaboration Fund: 2017-2018 and 2019-2021.

Institutional Review Board Statement: Not applicable.

Informed Consent Statement: Not applicable.

Data Availability Statement: All the results used in this work to support the conclusions of this study are included in the article.

Acknowledgments: We acknowledge Danilo Garrido Pérez for graphic design support.

Conflicts of Interest: The authors declare no conflict of interest. 


\section{References}

1. Alvar, J.; Vélez, I.D.; Bern, C.; Herrero, M.; Desjeux, P.; Cano, J.; Jannin, J.; de Boer, M. Leishmaniasis worldwide and global estimates of its incidence. PLoS ONE 2012, 7, e35671. [CrossRef]

2. Norman, F.F.; López-Vélez, R. Chagas disease: Comments on the 2018 PAHO Guidelines for diagnosis and management. J. Travel Med. 2019, 26, taz060. [CrossRef]

3. WHO. World Health Organization: Leishmaniasis and Chagas Disease. 2020. Available online: https://www.who.int/ news/item/30-01-2009-leishmaniasis-the-global-trend; https://www.who.int/news-room/fact-sheets/detail/chagas-disease(american-trypanosomiasis) (accessed on 1 May 2021).

4. Sangenito, L.S.; da Silva Santos, V.; d'Avila-Levy, C.M.; Branquinha, M.H.; Souza dos Santos, A.L.; de Oliveira, S.S.C. Leishmaniasis and Chagas Disease-Neglected Tropical Diseases: Treatment Updates. Curr. Top. Med. Chem. 2019, 19, 174-177. [CrossRef]

5. Aragão Horoiwa, T.; Cortez, M.; Sauter, I.P.; Migotto, A.; Bandeira, C.L.; Cerize, N.N.P.; de Oliveira, A.M. Sugar-based colloidal nanocarriers for topical meglumine antimoniate application to cutaneous leishmaniasis treatment: Ex vivo cutaneous retention and in vivo evaluation. Eur. J. Pharm. Sci. 2020, 147, 105295. [CrossRef]

6. $\quad$ Ferreira, T.C.S.; Sauter, I.P.; Borda-Samper, L.; Bentivoglio, E.; DaMata, J.P.; Taniwaki, N.N.; Orrego, P.R.; Araya, J.E.; Lincopan, N.; Cortez, M. Effect of DODAB Nano-Sized Cationic Bilayer Fragments against Leishmania amazonensis. Molecules 2020, $25,5741$. [CrossRef] [PubMed]

7. Luczywo, A.; Sauter, I.P.; da Silva Ferreira, T.C.; Cortez, M.; Romanelli, G.P.; Sathicq, G.; Asís, S.E. Microwave-assisted synthesis of 2-styrylquinoline-4-carboxylic acid derivatives to improve the toxic effect against Leishmania (Leishmania) amazonensis. J. Heterocycl. Chem. 2020, 58, 822-832. [CrossRef]

8. Geiger, A.; Bossard, G.; Sereno, D.; Pissarra, J.; Lemesre, J.L.; Vincendeau, P.; Holzmuller, P. Escaping deleterious immune response in their hosts: Lessons from trypanosomatids. Front. Immunol. 2016, 7, 212. [CrossRef]

9. De Morais, C.; Castro Lima, A.; Terra, R.; dos Santos, R.; Da-Silva, S.; Dutra, P. The dialogue of the host-parasite relationship: Leishmania spp. and Trypanosoma cruzi infection. Biomed. Res. Int. 2015, 1-19. [CrossRef]

10. Yoshida, N.; Cortez, M. Trypanosoma cruzi: Parasite and host cell signaling during the invasion process. Subcell. Biochem. 2008, 47, 82-91. [CrossRef] [PubMed]

11. Ramakrishnan, S.; Docampo, R. Membrane proteins in trypanosomatids involved in $\mathrm{Ca}^{2+}$ homeostasis and signaling. Genes 2018, 9, 304. [CrossRef]

12. Park, H.S.; Lee, S.C.; Cardenas, M.E.; Heitman, J. Calcium-Calmodulin-Calcineurin Signaling: A Globally Conserved Virulence Cascade in Eukaryotic Microbial Pathogens. Cell Host Microbe 2019, 26, 453-462. [CrossRef]

13. Klee, C.B.; Crouch, T.H.; Krinks, M.H. Calcineurin: A calcium- and calmodulin-binding protein of the nervous system. Proc. Natl. Acad. Sci. USA 1979, 76, 6270-6273. [CrossRef]

14. Klee, C.B.; Draetta, G.F.; Hubbard, M.J. Calcineurin. Adv. Enzymol. Relat. Areas Mol. Biol. 1988, 61, 149-200. [CrossRef] [PubMed]

15. Kincaid, R. Calmodulin-dependent protein phosphatases from microorganisms to man. A study in structural conservatism and biological diversity. Adv. Second. Messenger Phosphoprot. Res. 1993, 27, 1-23.

16. Creamer, T.P. Calcineurin. Cell Commun. Signal. 2020, 18, 1-12. [CrossRef]

17. Rusnak, F.; Mertz, P. Calcineurin: Form and function. Physiol. Rev. 2000, 80, 1483-1521. [CrossRef] [PubMed]

18. Crabtree, G.R. Calcium, calcineurin, and the control of transcription. J. Biol. Chem. 2001, 276, 2313-2316. [CrossRef] [PubMed]

19. Sikkink, R.; Haddy, A.; MacKelvie, S.; Mertz, P.; Litwiller, R.; Rusnak, F. Calcineurin subunit interactions: Mapping the calcineurin B binding domain on calcineurin A. Biochemistry 1995, 34, 8348-8356. [CrossRef]

20. Watanabe, Y.; Perrino, B.A.; Chang, B.H.; Soderling, T.R. Identification in the calcineurin A subunit of the domain that binds the regulatory B subunit. J. Biol. Chem. 1995, 270, 456-460. [CrossRef]

21. Kincaid, R.L.; Nightingale, M.S.; Martin, B.M. Characterization of a cDNA clone encoding the calmodulin-binding domain of mouse brain calcineurin. Proc. Natl. Acad. Sci. USA 1988, 85, 8983-8987. [CrossRef]

22. Guerini, D.; Montell, C.; Klee, C.B. Molecular cloning and characterization of the genes encoding the two subunits of Drosophila melanogaster calcineurin. J. Biol. Chem. 1992, 267, 22542-22549. [CrossRef]

23. Hashimoto, Y.; Perrino, B.A.; Soderling, T.R. Identification of an autoinhibitory domain in calcineurin. J. Biol. Chem. 1990, 265, 1924-1927. [CrossRef]

24. Kissinger, C.R.; Parge, H.E.; Knighton, D.R.; Lewis, C.T.; Pelletier, L.A.; Tempczyk, A.; Kalish, V.J.; Tucker, K.D.; Showalter, R.E.; Moomaw, E.W.; et al. Crystal structures of human calcineurin and the human FKBP12-FK506-calcineurin complex. Nature 1995, 378, 641-644. [CrossRef] [PubMed]

25. Aramburu, J.; Heitman, J.; Crabtree, G.R. Calcineurin: A central controller of signalling in eukaryotes. EMBO Rep. 2004, 5, 343-348. [CrossRef]

26. Schreiber, S.L.; Crabtree, G.R. The mechanism of action of cyclosporin A and FK506. Immunol. Today 1992, 13, 136-142. [CrossRef]

27. Ho, S.; Clipstone, N.; Timmermann, L.; Northrop, J.; Graef, I.; Fiorentino, D.; Nourse, J.; Crabtree, G.R. The mechanism of action of cyclosporin A and FK506. Clin. Immunol. Immunopathol. 1996, 80, S40-S45. [CrossRef]

28. Juvvadi, P.R.; Lee, S.C.; Heitman, J.; Steinbach, W.J. Calcineurin in fungal virulence and drug resistance: Prospects for harnessing targeted inhibition of calcineurin for an antifungal therapeutic approach. Virulence 2017, 8, 186-197. [CrossRef] 
29. Fraga, D.; Sehring, I.M.; Kissmehl, R.; Reiss, M.; Gaines, R.; Hinrichsen, R.; Plattner, H. Protein phosphatase 2B (PP2B, calcineurin) in Paramecium: Partial characterization reveals that two members of the unusually large catalytic subunit family have distinct roles in calcium-dependent processes. Eukaryot. Cell 2010, 9, 1049-1063. [CrossRef]

30. Stathopoulos-Gerontides, A.; Guo, J.J.; Cyert, M.S. Yeast calcineurin regulates nuclear localization of the Crz1p transcription factor through dephosphorylation. Genes Dev. 1999, 13, 798-803. [CrossRef]

31. Balaji, S.; Madan Babu, M.; Iyer, L.M.; Aravind, L. Discovery of the principal specific transcription factors of Apicomplexa and their implication for the evolution of the AP2-integrase DNA binding domains. Nucleic Acids Res. 2005, 33, 3994-4006. [CrossRef]

32. Araya, J.E.; Cornejo, A.; Orrego, P.R.; Cordero, E.M.; Cortéz, M.; Olivares, H.; Neira, I.; Sagua, H.; Franco da Silveira, J.; Yoshida, N.; et al. Calcineurin B of the human protozoan parasite Trypanosoma cruzi is involved in cell invasion. Microbes Infect. 2008, 10, 892-900. [CrossRef]

33. Orrego, P.R.; Olivares, H.; Cordero, E.M.; Bressan, A.; Cortez, M.; Sagua, H.; Neira, I.; González, J.; da Silveira, J.F.; Yoshida, N.; et al. A cytoplasmic new catalytic subunit of calcineurin in Trypanosoma cruzi and its molecular and functional characterization. PLoS Negl. Trop. Dis. 2014, 8, e2676. [CrossRef]

34. Naderer, T.; Dandash, O.; Mcconville, M.J. Calcineurin is required for Leishmania major stress response pathways and for virulence in the mammalian host. Mol. Microbiol. 2011, 80, 471-480. [CrossRef] [PubMed]

35. Mukhopadhyay, A.G.; Dey, C.S. Role of calmodulin and calcineurin in regulating flagellar motility and wave polarity in Leishmania. Parasitol. Res. 2017, 116, 3221-3228. [CrossRef]

36. Aslett, M.; Aurrecoechea, C.; Berriman, M.; Brestelli, J.; Brunk, B.P.; Carrington, M.; Depledge, D.P.; Fischer, S.; Gajria, B.; Gao, X.; et al. TriTrypDB: A functional genomic resource for the Trypanosomatidae. Nucleic Acids Res. 2010, 38, D457-D462. [CrossRef] [PubMed]

37. Moreno, V.R.; Agüero, F.; Tekiel, V.; Sánchez, D.O. The Calcineurin A homologue from Trypanosoma cruzi lacks two important regulatory domains. Acta Trop. 2007, 101, 80-89. [CrossRef] [PubMed]

38. Brenchley, R.; Tariq, H.; McElhinney, H.; Szöor, B.; Huxley-Jones, J.; Stevens, R.; Matthews, K.; Tabernero, L. The TriTryp phosphatome: Analysis of the protein phosphatase catalytic domains. BMC Genomics 2007, 8, 434. [CrossRef]

39. Leifso, K.; Cohen-Freue, G.; Dogra, N.; Murray, A.; McMaster, W.R. Genomic and proteomic expression analysis of Leishmania promastigote and amastigote life stages: The Leishmania genome is constitutively expressed. Mol. Biochem. Parasitol. 2007, 152, 35-46. [CrossRef] [PubMed]

40. Rice, P.; Longden, L.; Bleasby, A. EMBOSS: The european molecular biology open software suite. Trends Genet. 2000, 16, 276-277. [CrossRef]

41. Kumar, S.; Stecher, G.; Tamura, K. MEGA7: Molecular Evolutionary Genetics Analysis Version 7.0 for Bigger Datasets. Mol. Biol. Evol. 2016, 33, 1870-1874. [CrossRef]

42. Marchler-Bauer, A.; Lu, S.; Anderson, J.B.; Chitsaz, F.; Derbyshire, M.K.; DeWeese-Scott, C.; Fong, J.H.; Geer, L.Y.; Geer, R.C.; Gonzales, N.R.; et al. CDD: A Conserved Domain Database for the functional annotation of proteins. Nucleic Acids Res. 2011, 39, D225-D229. [CrossRef] [PubMed]

43. Marchler-Bauer, A.; Derbyshire, M.K.; Gonzales, N.R.; Lu, S.; Chitsaz, F.; Geer, L.Y.; Geer, R.C.; He, J.; Gwadz, M.; Hurwitz, D.I.; et al. CDD: NCBI's conserved domain database. Nucleic Acids Res. 2015, 43, D222-D226. [CrossRef] [PubMed]

44. Lu, S.; Wang, J.; Chitsaz, F.; Derbyshire, M.K.; Geer, R.C.; Gonzales, N.R.; Gwadz, M.; Hurwitz, D.I.; Marchler, G.H.; Song, J.S.; et al. CDD/SPARCLE: The conserved domain database in 2020. Nucleic Acids Res. 2020, 48, D265-D268. [CrossRef] [PubMed]

45. De Castro, E.; Sigrist, C.J.A.; Gattiker, A.; Bulliard, V.; Langendijk-Genevaux, P.S.; Gasteiger, E.; Bairoch, A.; Hulo, N. ScanProsite: Detection of PROSITE signature matches and ProRule-associated functional and structural residues in proteins. Nucleic Acids Res. 2006, 34, W362-W365. [CrossRef] [PubMed]

46. Hulo, N.; Bairoch, A.; Bulliard, V.; Cerutti, L.; Cuche, B.A.; De castro, E.; Lachaize, C.; Langendijk-Genevaux, P.S.; Sigrist, C.J.A. The 20 years of PROSITE. Nucleic Acids Res. 2008, 36, D245-D249. [CrossRef] [PubMed]

47. Gasteiger, E.; Hoogland, C.; Gattiker, A.; Duvaud, S.; Wilkins, M.R.; Appel, R.D.; Bairoch, A. Protein Identification and Analysis Tools on the ExPASy Server. In The Proteomics Protocols Handbook; Walker, J.M., Ed.; Humana Press: Totowa, NJ, USA, 2005.

48. Kyte, J.; Doolittle, R.F. A simple method for displaying the hydropathic character of a protein. J. Mol. Biol. 1982, 157, 105-132. [CrossRef]

49. Szklarczyk, D.; Gable, A.L.; Lyon, D.; Junge, A.; Wyder, S.; Huerta-Cepas, J.; Simonovic, M.; Doncheva, N.T.; Morris, J.H.; Bork, P.; et al. STRING v11: Protein-protein association networks with increased coverage, supporting functional discovery in genome-wide experimental datasets. Nucleic Acids Res. 2019, 47, D607-D613. [CrossRef]

50. Gazestani, V.H.; Yip, C.W.; Nikpour, N.; Berghuis, N.; Salavati, R. TrypsNetDB: An integrated framework for the functional characterization of trypanosomatid proteins. PLoS Negl. Trop. Dis. 2017, 11, e0005368. [CrossRef]

51. Horton, P.; Park, K.J.; Obayashi, T.; Fujita, N.; Harada, H.; Adams-Collier, C.J.; Nakai, K. WoLF PSORT: Protein localization predictor. Nucleic Acids Res. 2007, 35, W585-W587. [CrossRef]

52. Yu, C.S.; Cheng, C.W.; Su, W.C.; Chang, K.C.; Huang, S.W.; Hwang, J.K.; Lu, C.H. CELLO2GO: A web server for protein subCELlular lOcalization prediction with functional gene ontology annotation. PLoS ONE 2014, 9, e99368. [CrossRef]

53. Bendtsen, J.D.; Jensen, L.J.; Blom, N.; Von Heijne, G.; Brunak, S. Feature-based prediction of non-classical and leaderless protein secretion. Protein Eng. Des. Sel. 2004, 17, 349-356. [CrossRef] 
54. Liu, Z.; Cao, J.; Gao, X.; Ma, Q.; Ren, J.; Xue, Y. GPS-CCD: A novel computational program for the prediction of calpain cleavage sites. PLoS ONE 2011, 6, e19001. [CrossRef]

55. Blom, N.; Gammeltoft, S.; Brunak, S. Sequence and structure-based prediction of eukaryotic protein phosphorylation sites. J. Mol. Biol. 1999, 294, 1351-1362. [CrossRef] [PubMed]

56. Blom, N.; Sicheritz-Pontén, T.; Gupta, R.; Gammeltoft, S.; Brunak, S. Prediction of post-translational glycosylation and phosphorylation of proteins from the amino acid sequence. Proteomics 2004, 4, 1633-1649. [CrossRef] [PubMed]

57. Kakalis, L.T.; Kennedy, M.; Sikkink, R.; Rusnak, F.; Armitage, I.M. Characterization of the calcium-binding sites of calcineurin B. FEBS Lett. 1995, 362, 55-58. [CrossRef]

58. Szöör, B. Trypanosomatid protein phosphatases. Mol. Biochem. Parasitol. 2010, 173, 53-63. [CrossRef]

59. Ferreira, T.C.S.; Siess-Portugal, C.; Orrego, P.R.; Araya, J.E.; Cortez, M. Papel de calcineurinas na interação Leishmania-macrófago. In Atualidades em Medicina Tropical no Brasil: Protozoários; de Oliveira Meneguetti, D.U., de Oliveira, J., Aranha Camargo, L.M., Eds.; Stricto Sensu: Rio Branco, Brazil, 2020; pp. 319-339. ISBN 978-65-86283-13-6.

60. Baksh, S.; Burakoff, S.J. The role of calcineurin in lymphocyte activation. Semin. Immunol. 2000, 12, 405-415. [CrossRef] [PubMed]

61. Kurotani, A.; Tokmakov, A.A.; Sato, K.I.; Stefanov, V.E.; Yamada, Y.; Sakurai, T. Localization-specific distributions of protein pI in human proteome are governed by local pH and membrane charge. BMC Mol. Cell Biol. 2019, 20, 36. [CrossRef]

62. Kiraga, J.; Mackiewicz, P.; Mackiewicz, D.; Kowalczuk, M.; Biecek, P.; Polak, N.; Smolarczyk, K.; Dudek, M.R.; Cebrat, S. The relationships between the isoelectric point and: Length of proteins, taxonomy and ecology of organisms. BMC Genomics 2007, 8, 163. [CrossRef]

63. Norris, C.M. Calpain interactions with the protein phosphatase calcineurin in neurodegeneration. In Role of Proteases in Cellular Dysfunction; Dhalla, N., Chakraborti, S., Eds.; Advances in Biochemistry in Health and Disease; Springer: New York, NY, USA, 2014; Volume 8, ISBN 9781461490999. [CrossRef]

64. Wu, H.Y.; Tomizawa, K.; Matsui, H. Calpain-calcineurin signaling in the pathogenesis of calcium-dependent disorder. Acta Med. Okayama 2007, 61, 123-137. [CrossRef]

65. Wu, H.Y.; Tomizawa, K.; Oda, Y.; Wei, F.Y.; Lu, Y.F.; Matsushita, M.; Li, S.T.; Moriwaki, A.; Matsui, H. Critical role of calpainmediated cleavage of calcineurin in excitotoxic neurodegeneration. J. Biol. Chem. 2004, 279, 4929-4940. [CrossRef] [PubMed]

66. Liu, P.; Huang, C.; Jia, Z.; Yi, F.; Yu, D.-Y.; Wei, Q. Non-catalytic domains of subunit A negatively regulate the activity of calcineurin. Biochimie 2005, 87, 215-221. [CrossRef] [PubMed]

67. Ding, F.; Li, X.; Li, B.; Guo, J.; Zhang, Y.; Ding, J. Calpain-mediated cleavage of calcineurin in puromycin aminonucleoside-induced podocyte injury. PLoS ONE 2016, 11, e0155504. [CrossRef]

68. Sangenito, L.S.; Ennes-Vidal, V.; Marinho, F.A.; Da Mota, F.F.; Santos, A.L.; D'Avila-Levy, C.M.; Branquinha, M.H. Arrested growth of Trypanosoma cruzi by the calpain inhibitor MDL28170 and detection of calpain homologues in epimastigote forms. Parasitology 2009, 136, 433-441. [CrossRef] [PubMed]

69. Ennes-Vidal, V.; Menna-Barreto, R.F.S.; Santos, A.L.S.; Branquinha, M.H.; d'Avila-Levy, C.M. Effects of the calpain inhibitor MDL28170 on the clinically relevant forms of Trypanosoma cruzi in vitro. J. Antimicrob. Chemother. 2010, 65, 1395-1398. [CrossRef] [PubMed]

70. Ennes-Vidal, V.; Menna-Barreto, R.F.S.; Santos, A.L.S.; Branquinha, M.H.; d'Avila-Levy, C.M. MDL28170, a calpain inhibitor, affects Trypanosoma cruzi metacyclogenesis, ultrastructure and attachment to Rhodnius prolixus midgut. PLoS ONE 2011, 6, e18371. [CrossRef]

71. Marinho, F.A.; Gonçalves, K.C.S.; Oliveira, S.S.C.; Gonçalves, D.S.; Matteoli, F.P.; Seabra, S.H.; Oliveira, A.C.S.; Bellio, M.; Oliveira, S.S.; Souto-Padrón, T.; et al. The calpain inhibitor MDL28170 induces the expression of apoptotic markers in Leishmania amazonensis promastigotes. PLoS ONE 2014, 9, e87659. [CrossRef]

72. Branquinha, M.; Marinho, F.; Sangenito, L.; Oliveira, S.; Goncalves, K.; Ennes-Vidal, V.; d'Avila-Levy, C.; Santos, A. Calpains: Potential targets for alternative chemotherapeutic intervention against human pathogenic trypanosomatids. Curr. Med. Chem. 2013, 20, 3174-3185. [CrossRef]

73. Ono, Y.; Saido, T.C.; Sorimachi, H. Calpain research for drug discovery: Challenges and potential. Nat. Rev. Drug Discov. 2016, 15, 854-876. [CrossRef]

74. Calalb, M.B.; Kincaid, R.L.; Soderling, T.R. Phosphorylation of calcineurin: Effect on calmodulin binding. Biochem. Biophys. Res. Commun. 1990, 172, 551-556. [CrossRef]

75. Colbran, R.J.; Soderling, T.R. Calcium/calmodulin-independent autophosphorylation sites of calcium/calmodulin-dependent protein kinase II. Studies on the effect of phosphorylation of threonine 305/306 and serine 314 on calmodulin binding using synthetic peptides. J. Biol. Chem. 1990, 265, 11213-11219. [CrossRef]

76. Jaureguia, E.; Du, L.; Gleasonc, C.; Poovaiah, B.W. Autophosphorylation of calcium/calmodulin-dependent protein kinase (CCaMK) at S343 or S344 generates an intramolecular interaction blocking the CaM-binding. Plant Signal. Behav. 2017, 12, e1343779. [CrossRef] [PubMed]

77. Perrino, B.A. Regulation of calcineurin phosphatase activity by its autoinhibitory domain. Arch. Biochem. Biophys. 1999, 372, 159-165. [CrossRef]

78. Li, S.J.; Wang, J.; Ma, L.; Lu, C.; Wang, J.; Wu, J.W.; Wang, Z.X. Cooperative autoinhibition and multi-level activation mechanisms of calcineurin. Cell Res. 2016, 26, 336-349. [CrossRef] [PubMed] 
79. Montenegro, M.; Cardenas, C.; Cuervo, C.; Bernal, C.; Grisard, E.C.; Thomas, M.C.; Lopez, M.C.; Puerta, C.J. Molecular characterization of calcineurin B from the non-virulent Trypanosoma rangeli kinetoplastid indicates high gene conservation. Mol. Biol. Rep. 2013, 40, 4901-4912. [CrossRef] [PubMed]

80. Feng, B.; Stemmer, P.M. Interactions of calcineurin A, calcineurin B, and Ca ${ }^{2+}$. Biochemistry 1999, 38, 12481-12489. [CrossRef] [PubMed]

81. Zhou, Y.; Yang, W.; Kirberger, M.; Lee, H.W.; Ayalasomayajula, G.; Yang, J.J. Prediction of EF-hand calcium-binding proteins and analysis of bacterial EF-hand proteins. Proteins Struct. Funct. Genet. 2006, 65, 643-655. [CrossRef]

82. Yang, S.A.; Klee, C.B. Low affinity $\mathrm{Ca}^{2+}$-Binding sites of calcineurin B mediate conformational changes in calcineurin A. Biochemistry 2000, 39, 16147-16154. [CrossRef]

83. Natarajan, K.; Ness, J.; Wooge, C.H.; Janovick, J.A.; Conn, P.M. Specific identification and subcellular localization of three calmodulin-binding proteins in the rat gonadotrope: Spectrin, caldesmon, and calcineurin. Biol. Reprod. 1991, 44, 43-52. [CrossRef]

84. Politino, M.; King, M.M. Calcium- and calmodulin-sensitive interactions of calcineurin with phospholipids. J. Biol. Chem. 1987, 262, 10109-10113. [CrossRef]

85. Shibasaki, F.; Price, E.R.; Milan, D.; McKeon, F. Role of kinases and the phosphatase calcineurin in the nuclear shuttling of transcription factor NF-AT4. Nature 1996, 382, 370-373. [CrossRef]

86. Usuda, N.; Arai, H.; Sasaki, H.; Hanai, T.; Nagata, T.; Muramatsu, T.; Kincaid, R.L.; Higuchi, S. Differential subcellular localization of neural isoforms of the catalytic subunit of calmodulin-dependent protein phosphatase (calcineurin) in central nervous system neurons: Immunohistochemistry on formalin-fixed paraffin sections employing antigen retri. J. Histochem. Cytochem. 1996, 44, 13-18. [CrossRef]

87. Bueno, O.F.; Brandt, E.B.; Rothenberg, M.E.; Molkentin, J.D. Defective T cell development and function in calcineurin A $\beta$-deficient mice. Proc. Natl. Acad. Sci. USA 2002, 99, 9398-9403. [CrossRef]

88. Gooch, J.L.; Toro, J.J.; Guler, R.L.; Barnes, J.L. Calcineurin A- $\alpha$ but not A- $\beta$ is required for normal kidney development and function. Am. J. Pathol. 2004, 165, 1755-1765. [CrossRef]

89. Singh, S.; More, K.R.; Chitnis, C.E. Role of calcineurin and actin dynamics in regulated secretion of microneme proteins in Plasmodium falciparum merozoites during erythrocyte invasion. Cell. Microbiol. 2014, 16, 50-63. [CrossRef] [PubMed]

90. Banerjee, C.; Sarkar, D.; Bhaduri, A. $\mathrm{Ca}^{2+}$ and calmodulin-dependent protein phosphatase from Leishmania donovani. Parasitology 1999, 118, 567-573. [CrossRef] [PubMed]

91. Leitherer, S.; Clos, J.; Liebler-Tenorio, E.M.; Schleicher, U.; Bogdan, C.; Soulat, D. Characterization of the protein tyrosine phosphatase LmPRL-1 secreted by Leishmania major via the exosome pathway. Infect. Immun. 2017, 85, e00084-17. [CrossRef] [PubMed]

92. Fernandes, A.C.S.; Soares, D.C.; Saraiva, E.M.; Meyer-Fernandes, J.R.; Souto-Padrón, T. Different secreted phosphatase activities in Leishmania amazonensis. FEMS Microbiol. Lett. 2013, 340, 117-128. [CrossRef]

93. Soulat, D.; Bogdan, C. Function of macrophage and parasite phosphatases in leishmaniasis. Front. Immunol. 2017, 8, 1838. [CrossRef]

94. Kolukisaoglu, Ü.; Weinl, S.; Blazevic, D.; Batistic, O.; Kudla, J. Calcium sensors and their interacting protein kinases: Genomics of the Arabidopsis and rice CBL-CIPK signaling networks. Plant Physiol. 2004, 134, 43-58. [CrossRef]

95. Silverman, J.M.; Clos, J.; De'Oliveira, C.C.; Shirvani, O.; Fang, Y.; Wang, C.; Foster, L.J.; Reiner, N.E. An exosome-based secretion pathway is responsible for protein export from Leishmania and communication with macrophages. J. Cell Sci. 2010, 123, 842-852. [CrossRef]

96. Atayde, V.; Aslan, H.; Townsend, S.; Hassani, K.; Kamhawi, S.; Olivier, M. Exosome secretion by the parasitic protozoan Leishmania within the sand fly midgut. Cell Rep. 2015, 13, 957-967. [CrossRef] [PubMed]

97. Bayer-Santos, E.; Aguilar-Bonavides, C.; Rodrigues, S.P.; Cordero, E.M.; Marques, A.F.; Varela-Ramirez, A.; Choi, H.; Yoshida, N.; Da Silveira, J.F.; Almeida, I.C. Proteomic analysis of Trypanosoma cruzi secretome: Characterization of two populations of extracellular vesicles and soluble proteins. J. Proteome Res. 2013, 12, 883-897. [CrossRef] [PubMed]

98. Sauter, I.P.; Madrid, K.G.; de Assis, J.B.; Sá-Nunes, A.; Torrecilhas, A.C.; Staquicini, D.I.; Pasqualini, R.; Arap, W.; Cortez, M. TLR9/MyD88/TRIF signaling activates host immune inhibitory CD200 in Leishmania infection. JCI Insight 2019, 4, e126207. [CrossRef]

99. Rossi, I.V.; Ferreira Nunes, M.A.; Vargas-Otalora, S.; da Silva Ferreira, T.C.; Cortez, M.; Ramirez, M.I. Extracellular vesicles during TriTryps infection: Complexity and future challenges. Mol. Immunol. 2021, 132, 172-183. [CrossRef] [PubMed]

100. Neves, R.F.C.; Fernandes, A.C.S.; Meyer-Fernandes, J.R.; Souto-Padrón, T. Trypanosoma cruzi-secreted vesicles have acid and alkaline phosphatase activities capable of increasing parasite adhesion and infection. Parasitol. Res. 2014, 113, $2961-2972$. [CrossRef] [PubMed]

101. Ramírez-Toloza, G.; Aguilar-Guzmán, L.; Valck, C.; Abello, P.; Ferreira, A. Is it all that bad when living with an intracellular protozoan? the role of Trypanosoma cruzi calreticulin in angiogenesis and tumor growth. Front. Oncol. 2015, 4, 382. [CrossRef] [PubMed]

102. Kumar, R.; Bunn, P.T.; Singh, S.S.; Ng, S.S.; Montes de Oca, M.; De Labastida Rivera, F.; Chauhan, S.B.; Singh, N.; Faleiro, R.J.; Edwards, C.L.; et al. Type I Interferons Suppress Anti-parasitic Immunity and Can Be Targeted to Improve Treatment of Visceral Leishmaniasis. Cell Rep. 2020, 30, 2512-2525. [CrossRef] 
103. Rashidi, S.; Fernández-Rubio, C.; Manzano-Román, R.; Mansouri, R.; Shafiei, R.; Ali-Hassanzadeh, M.; Barazesh, A.; Karimazar, M.; Hatam, G.; Nguewa, P. Potential therapeutic targets shared between leishmaniasis and cancer. Parasitology 2021, 148, 655-671. [CrossRef] [PubMed]

104. Cortez, M.; Huynh, C.; Fernandes, M.C.; Kennedy, K.A.; Aderem, A.; Andrews, N.W. Leishmania promotes its own virulence by inducing expression of the host immune inhibitory ligand CD200. Cell Host Microbe 2011, 9, 463-471. [CrossRef] [PubMed]

105. Hyenne, V.; Ghoroghi, S.; Collot, M.; Bons, J.; Follain, G.; Harlepp, S.; Mary, B.; Bauer, J.; Mercier, L.; Busnelli, I.; et al. Studying the Fate of Tumor Extracellular Vesicles at High Spatiotemporal Resolution Using the Zebrafish Embryo. Dev. Cell 2019, 48, 554-572. [CrossRef]

106. Caner, A.; Sadıqova, A.; Erdoğan, A.; Namlıses, D.; Nalbantsoy, A.; Oltulu, F.; Toz, S.; Yiğittürk, G.; Ozkök, E.; Gunduz, C.; et al. Targeting of antitumor immune responses with live-attenuated Leishmania strains in breast cancer model. Breast Cancer 2020, 27, 1082-1095. [CrossRef]

107. Zhao, H.; Achreja, A.; Iessi, E.; Logozzi, M.; Mizzoni, D.; Di Raimo, R.; Nagrath, D.; Fais, S. The key role of extracellular vesicles in the metastatic process. Biochim. Biophys. Biochim. Biophys. Acta (BBA) Rev. Cancer 2018, 1869, 64-77. [CrossRef] [PubMed]

108. Su, Z.; DeWitt, J.P. The multiple mechanism of anti-tumor function of calcineurin B subunit. Jacobs J. Mol. Transl. Med. 2015, 1, 1-3.

109. Liu, L.; Su, Z.; Xin, S.; Cheng, J.; Li, J.; Xu, L.; Wei, Q. The calcineurin B subunit (CnB) is a new ligand of integrin $\alpha M$ that mediates CnB-induced Apo2L/TRAIL expression in macrophages. J. Immunol. 2012, 188, 238-247. [CrossRef]

110. Yang, J.; Qin, N.; Zhang, H.; Yang, R.; Xiang, B.; Wei, Q. Cellular uptake of exogenous calcineurin B is dependent on TLR4/MD2/CD14 complexes, and CnB is an endogenous ligand of TLR4. Sci. Rep. 2016, 6, 24346. [CrossRef] [PubMed]

111. Guo, Y.; Huang, Y.; Tian, S.; Xie, X.; Xing, G.; Fu, J. Genetically engineered drug rhCNB induces apoptosis and cell cycle arrest in both gastric cancer cells and hepatoma cells. Drug Des. Dev. Ther. 2018, 12, 2567-2575. [CrossRef] [PubMed]

112. Yang, J.; Gao, Y.; Zhu, Z.; Qin, N.; Wei, Q. Identification of a targeting-delivery peptide based on rhCNB. J. Pept. Sci. 2019, 25, e3159. [CrossRef] [PubMed]

113. Pereira, P.J.B.; Vega, M.C.; González-Rey, E.; Fernández-Carazo, R.; Macedo-Ribeiro, S.; Gomis-Rüth, F.X.; González, A.; Coll, M. Trypanosoma cruzi macrophage infectivity potentiator has a rotamase core and a highly exposed $\alpha$-helix. EMBO Rep. 2002, 3, 88-94. [CrossRef]

114. Moro, A.; Ruiz-Cabello, F.; Fernández-Cano, A.; Stock, R.P.; Gonzalez, A. Secretion by Trypanosoma cruzi of a peptidyl-prolyl cis-trans isomerase involved in cell infection. EMBO J. 1995, 14, 2483-2490. [CrossRef]

115. Kulkarni, M.M.; Karafova, A.; Kamysz, W.; Schenkman, S.; Pelle, R.; McGwire, B.S. Secreted trypanosome cyclophilin inactivates lytic insect defense peptides and induces parasite calcineurin activation and infectivity. J. Biol. Chem. 2013, 288, 8772-8784. [CrossRef] [PubMed]

116. Field, M.C.; Carrington, M. The trypanosome flagellar pocket. Nat. Rev. Microbiol. 2009, 7, 775-786. [CrossRef] [PubMed]

117. Murta, A.C.; Persechini, P.M.; Padron, T.d.S.; de Souza, W.; Guimarães, J.A.; Scharfstein, J. Structural and functional identification of GP57/51 antigen of Trypanosoma cruzi as a cysteine proteinase. Mol. Biochem. Parasitol. 1990, 43, 27-38. [CrossRef]

118. Baba, Y.; Hirukawa, N.; Tanohira, N.; Sodeoka, M. Structure-based design of a highly selective catalytic site-directed inhibitor of Ser/Thr protein phosphatase 2B (calcineurin). J. Am. Chem. Soc. 2003, 125, 9740-9749. [CrossRef]

119. Baba, Y.; Hirukawa, N.; Sodeoka, M. Optically active cantharidin analogues possessing selective inhibitory activity on Ser/Thr protein phosphatase 2B (calcineurin): Implications for the binding mode. Bioorg. Med. Chem. 2005, 13, 5164-5170. [CrossRef] [PubMed] 